\title{
Erratum to: Trends in Psychological/Psychiatric Injury and Law: Continuing Education, Practice Comments, Recommendations
}

\author{
Gerald Young
}

Published online: 24 March 2011

(C) Springer Science+Business Media, LLC. 2011

Erratum to: Psychol. Inj. and Law (2010) 3:323-355
DOI 10.1007/s12207-010-9092-x

\begin{abstract}
This literature review of the major topics in the field of psychological/psychiatric injury and law is aimed at developing practice in the area. The field is a fastdeveloping one, with over ten major topics that it needs to integrate. In particular, the present review focuses on current work on: law (evidence, tort); forensic psychology; assessment and testing; psychological injuries (posttraumatic stress disorder, chronic pain, traumatic brain injury, other); the APA DSM-5 draft (Diagnostic and statistical manual of mental disorders; American Psychiatric Association 2010); malingering; causality; multicultural considerations; disability; the American Medical Association (AMA) Guides to the evaluation of permanent impairment (Rondinelli et al. 2008); models; and treatment. At the end of each section of the article, practice comments introduce critical issues in applying the research to psychological work in the area. Whether undertaking tort evaluations, disability, and treatment plan assessments or treating individuals with psychological injuries, the professional needs state-of-the-art information in all the areas listed in
\end{abstract}

This paper, originally published in Psychological Injury and Law, Volume 3, Number 4, December 2010, contained several paragraphs that were misplaced and some additional author corrections. The corrected version of this paper is reprinted here in its entirety.

The online version of the original article can be found at http://dx.doi. org/10.1007/s12207-010-9092-x.

\section{G. Young $(\bowtie)$}

Department of Psychology, Glendon College, York University,

2275 Bayview Ave,

Toronto, ON, Canada M4N 3M6

e-mail: gyoung@glendon.yorku.ca order to remain scientifically informed, comprehensive, and impartial. The article concludes with recommendations for an integrated field in psychological/psychiatric injury and law, study in the field, research in its major areas, best practice policies, for example in assessment and treatment, and model building.

Keywords Psychological injury - Literature review. Practice recommendations $\cdot$ Court

\section{Introduction}

The purpose of the present literature review is to provide a state-of-the-art introduction and commentary on recent research in all the major areas of the field of psychologi$\mathrm{cal} /$ psychiatric injury and law. This represents the first time, as far as is known, such a comprehensive review has been undertaken in all the major areas of the field in one source in a journal article. In addition, the article provides practice comments and recommendations based on the review, and this represents the first time, as far as is known, one source has attempted this task for all these areas. The article is aimed at the young professional and graduate student in psychology, as well those needing continuing education, in addition to practitioners in other areas such as in psychiatry and in law. In this regard, it serves as a tutorial for these other professions. More seasoned researchers in psychology as well as psychological practitioners in the area will find the review useful as an update to the field and as an integration of its diverse areas.

Note that in this global review of articles and book chapters published recently, it is impossible to cover all aspects of contending opinions or contentious issues. Because it is the first article in any journal covering all 
major areas of psychological/psychiatric injury and law, inevitably some topics are covered in less depth than others. In addition, space limitations are a factor in this regard. We expect further review articles with practice implications in the journal, but not globally; rather, they will be on separate journal topics. If they are annual, involve student participation, or elicit reader feedback, that would be acceptable. Given the overview nature of the article, it will have both strengths and weaknesses, but perceptions of these will not be uniform, partly given the forensic legal divide.

Psychological/psychiatric injuries concern chronic pain, posttraumatic stress, traumatic brain injury, and related conditions that develop after events at claim. Assessment should examine response bias, including of possible malingering. When the disability is considered permanent, tort or related legal actions follow. Practitioners need to know leading edge legal and forensic work, best assessment practices, valid diagnosis, and criteria of impairment and disability. The role of functionality and quality of life in establishing outcome and losses is emphasized in this type of work. This article presents recent scientific work in these areas while addressing contentious issues in this adversarial field.

For example, for law, what recent developments have taken place in practice in tort cases and in evidence law? What do we mean by pain and suffering? What is forensic psychology/psychiatry, and how is it applied to the civil setting as opposed to the criminal one? What is needed to establish professional competency in the area? What practice procedures need to be adopted to meet professional regulations and guidelines? What does it mean that it calls for impartial, comprehensive assessments?

In evaluation, what are the most reliable and valid instruments? Are they normed on populations applicable to this type of practice? What are the best instruments to use to detect possible malingering? Should the term be abandoned and replaced by others involving feigning? Do the tests used in the detection of malingering and related response biases take care to minimize false positives?

In diagnosis, what are some conundrums, and wither the DSM-V (Diagnostic and statistical manual of mental disorders, American Psychiatric Association, planned for 2013)? Does chronic pain fit the medical model, biopsychosocial model, or both (Gatchel et al. 2007; Melzack and Katz 2006)? Does posttraumatic stress disorder (PTSD) include as an entry point general life stressors, or should they be excluded to avoid "bracket creep" (McNally 2003)? Are there neurological findings that support its validity? Or, is it only a reflection of a preexisting negativity (Koch et al. 2006)?

Do some individuals with mild traumatic brain injury (mTBI) develop post-concussive syndrome and constitute the "miserable minority" (Ruff and Jamora 2009)? How can this syndrome be explained, e.g., is there residual pathophysiology that leads to outcomes that are compensable? Which of the brain scanning techniques are acceptable in court? What is the future of neurolaw in this area? Do the neuropsychological tests in the area possess ecological validity? Is cognitive rehabilitation effective?

In disability determination, the 2008 AMA Guides to the evaluation of permanent impairment (Rondinelli et al. 2008) are used widely, but can they be challenged for validity? In disability work, how relevant is it to investigate perceived sense of injustice, and how is it measured? What are the critical ingredients of disability and vocational assessments?

For each type of psychological injury, which psychopharmacological medications and which type of psychotherapy or intervention treat it best? How can clinicians improve their treatment plans and assessments in light of the growing information in the field? In treatment, what are dismantling studies revealing about its critical components?

Psychologists have engaged in this type of work since the adversarial divide was apparent in the area, across the defense and plaintiff sides in tort and related civil legal venues. However, the field of personal or psychological and psychiatric injury and law has only recently coalesced into a coherent discipline with its own books (e.g., Koch et al. 2006; Schultz and Gatchel 2005; Young et al. 2006, 2007), its own journal (Psychological Injury and Law; springer. com), and its own society (Association for Scientific Advancement in Psychological Injury and Law; ASAPIL; www.asapil.org). This article reviews recent trends in the literature in each of the major areas in the practice of psychological injury and law, helping to better prepare the reader for excellence in practice in this fast-growing field.

\section{Recent Literature Practice Comments}

Law and Psychological/Psychiatric Injury

Review Judges function as gatekeepers of evidence presented to court, ruling upon admissibility challenges that involve definitions of acceptable as opposed to poor or "junk" science, pursuant to standards outlined in the United States Supreme Court case of Daubert v. Merrell Dow Pharmaceuticals (1993). Daubert lists four primary criteria of acceptable science in court, but the evidence law in many jurisdictions still is based on Frye's v. United States (1923) criteria of general acceptance. Nevertheless, even in Frye states, it is incumbent on practitioners in law and in mental health to know Daubert's admissibility criteria of good science. Moreover, mental health practitioners should be familiar with the discrete stages of the civil litigation process and the contrasting professional obligations of 
members of differing professions and roles involved (Finch et al. 2008).

Faust et al. (2010) reviewed courtroom decisions related to the admissibility of behavioral science evidence. They pointed out the difficulty in the translation of legal concepts into the scientific arena, and vice versa. Concepts, meanings, and language in one domain are not necessarily similar or the same in other domains. The classic example refers to the different definitions of reliability in law and in behavioral science. In behavioral science, it refers to consistency in data. However, in law, it refers to validity of the data, which is especially confusing for mental health professionals working in the legal system (for psychologists, validity refers to soundness, accuracy, trustworthiness, and whether what is involved is about or measuring what it is supposed to; also see Young and Kane 2007).

Evidence law changed greatly with the Daubert (1993) ruling, which has been incorporated into the federal rules of evidence, such as Rule 702 (United States Government Printing Office 2009). Daubert (1993) has led to Kumho Tire v. Carmichael (1999) and General Electric v. Joiner (1997). These three rulings are commonly referred to as the Daubert trilogy, and there have been other rulings such as the Daubert II (Daubert v. Merrell Dow Pharmaceuticals 1995). The major Daubert factors related to admissibility concern whether the evidence reaches acceptable criteria related to (a) testability, (b) error rate, (c) peer review, and (d) general acceptance. The judge involved must now serve as the scientific gatekeeper according to these criteria, in establishing whether the evidence is relevant, reliable, helpful, and fit, so that it is more probative rather than prejudicial.

Faust et al. (2010) discussed recent decisions related to the admissibility and interpretations of Daubert. For example, if a method involved in the evidence cannot be tested and therefore has no known error rate, could the education, experience and personal observations of the expert proffering testimony in a case offset these scientific lacunae? Various legal decisions show that judges involved vary in the application of relevant standards and criteria in Daubert admissibility challenges pertaining to issues such as these. On the one hand, the authors concluded that the science might not have arrived at definitive conclusions about an area of study. This makes the task of the trier of fact that much more difficult. On the other hand, the authors maintained that clinical judgment, by itself, cannot properly substitute for objective methods derived from scientific study.

Sinclair (2010) examined standards for admissibility in court. In terms of the determination of causality of workrelated injury and illness, they supported an evidence-based approach, in particular, and the use of a guide of work related disease (Kusnetz and Hutchison 1979).
Practice Comment Evidence law is in flux, as is tort law. For example, recent decisions involving admissibility vary in terms of whether professional experience is an admissible basis of testimony as an expert (Faust et al. 2010). Also, the tort reform that is taking place across states is capping compensation for "pain and suffering" (Schatman and Sullivan 2010). Professionals in the field, whether mental health professionals or attorneys, need to keep abreast of these developments in order to determine the impact of the changes and work effectively in the field. The changes take place locally for the most part, at the level of lower courts and in states. It is rare to encounter major legal decisions federally. However, the Federal Rules of Evidence change on a consistent basis and should be included in the basic knowledge base of professionals in psychological/psychiatric injury and law.

By keeping up-to-date with the literature, as with articles such as these, and by reading the appropriate journals, the task of working effectively in this field is facilitated. The area of psychological/psychiatric injury and law is a practice minefield, and it has slippery slopes that lead to the adversarial divide. Aside from knowing the mental health side of matters, practitioners should be up-to-date in their knowledge of legal issues, case law, terminology, legal tests, difficulties in translating them into mental health terms, etc.

\section{Forensics and Psychological/Psychiatric Injury}

Review Ackerman (2010) provided a useful description of forensic assessment that applies to psychological and psychiatric injury. He referred to these cases as involving personal injury, but that term is more associated with the legal approach to the question. Ackerman reviewed the basic laws that govern admissibility of evidence to court, especially the Daubert trilogy. He pointed out that not all states have adopted the Daubert admissibility standards, so the forensic assessor should be aware whether the older legal test of general acceptance alone, as per Frye (1923), applies in one's jurisdiction of practice, although Daubert guidelines should be used no matter what the state [I would add, or province].

Forensic assessors should be aware of the codes and guidelines extant in the field, even though these codes and guidelines might not be mandated by their professional governing bodies, including the American Psychological Association (APA). The major codes/guidelines in the psychological/psychiatric injury field include: the APA's Ethical Principals of Psychologists and Code of Conduct (American Psychological Association 2002) and the Specialty Guidelines for Forensic Psychology (Committee on the Revision of the Specialty Guidelines for Forensic Psychology 2010). 
Ackerman pointed out that these guidelines and codes have been strongly influenced by Daubert, as has the empirically supported best practices movement. Although codes and guidelines are aspirational, the courts typically look at them as appropriate standards of care. Indeed, a court order could ask a psychologist to undertake an activity that violates the APA code of ethics. Ackerman maintained that the court order "supersedes" the Code, and the psychologist should take steps to explain this and protect against any future actions in court (for a nuanced view of the relationship between ethical and legal obligations, see Pope and Vasquez 2011).

An important code is 9.01 (901a, APA 2002, p. 1071), which concerns foundations for assessments. It stipulates that psychologists base their opinions, including in forensic reports and testimony, "on information and techniques sufficient to substantiate their findings." Ackerman (2010) maintained that this implies that professional opinions should be supported by scientific data, and it adds that assessment techniques based on poor or "junk" science have no place in practice or court. In this regard, for example, in order to assess individuals claiming posttraumatic stress disorder, the assessor should use reliable and valid instruments that include scales that verify respondent validity (e.g., exaggerating or minimizing symptoms; that is, faking "bad" or "good," respectively). The MMPI-2 personality test (Minnesota Multiphasic Personality Inventory) and its family of $F$ tests can be used for this purpose (Butcher et al. 1989, 2001). There are also specialized PTSD instruments with such scales, for example, the Detailed Assessment of Posttraumatic Stress (DAPS; Briere 2001).

Kane (2010) addressed the evaluation of malingering. He advised conducting a comprehensive assessment to rule it in or out. Assessors should be cautious in their formulation about malingering if the evidence supports concluding it is present because alternate explanations should be ruled out. According to Kane, the definition of malingering in the DSM-IV-TR (American Psychiatric Association 2000) is problematic, and it leads to a false positive rate of about $80 \%$ (Nicholson and Martelli 2007). Rogers' (2008) definition indicates that malingering involves deliberate fabrication or gross exaggeration. According to Kane, Young (2007) reviewed the literature on its frequency, and estimates varied from $2 \%$ to $64 \%$, which indicates the difficulty in researching it. Among other instruments, the MMPI-2 (Butcher et al. 1989, 2001), the Personality Assessment Inventory (PAI; Morey 1991, 2007), the Structured Interview of Reported Symptoms (SIRS; Rogers et al. 1992), and the Test of Malingered Memory (TOMM; Tombaugh 1996) can help in detecting its presence. Sellbom and Bagby (2008) advised against using the Millon Clinical Multiaxial Inventory-III Manual (MCMI III; Millon 1997; Millon et al. 2006) in this context.
Heilbrun et al. (2009) listed the foundational principles that should guide forensic mental health assessment. They emphasized the need to adopt a scientific approach, both in conducting the evaluation and in arriving at conclusions. The authors reviewed and integrated the following sources (in the order indicated) on forensic mental health assessment in elucidating their principles: Simon and Gold (2004), Melton et al. (2007), Heilbrun (2001), and Brodsky (e.g., 2004). Their integration consisted of 38 principles grouped into six categories: general and specific (preparation of the case, data collection, data interpretation, written communication, and testimony). For example, for the first category, forensic assessors should be familiar with the scientific literature, impartial, unbiased, and not adversarial. For the third, assessment procedures should be relevant, reliable, and valid. Most importantly, for the fourth category, the assessor should evaluate response style, which includes potential malingering. In addition, functional abilities as well as clinical condition should be evaluated. Causal connection should be evaluated using both individual, or idiographic, and population-level, or nomothetic, information. Scientific reasoning should be used to establish the relationship between clinical condition, functional capacity, and causal connection.

Practice Comment The primary role of training in forensic psychology in cases of psychological/psychiatric injury and law pertains to knowledge of the court system and how mental health professionals can serve the court in the adjudication of cases. Experts require the appropriate qualifications for the case at hand and must conduct comprehensive, impartial assessments grounded in scientific methodology and conclusions. Forensic psychology provides guidelines of professional practice beyond those of the American Psychological Association. Psychologists working in the area include rehabilitation psychologists, trauma psychologists, neuropsychologists, psychovocational assessors and counselors, etc. Whatever their primary background, mental health practitioners working in the area should be steeped in knowledge of forensic psychology and practice according to their strictures and guidelines. This journal aspires to disseminate state-of-the-art knowledge about psychology to practitioners in the area, especially in forensics and how it applies to the other areas of psychological/psychiatric injury and law. This is especially evident in the next section in testing.

Overview The article begins with the areas of law and forensic psychology because these areas form the basis of practice in the field of psychological/psychiatric injury and law. Both sections indicate the changing nature of the discipline and the need to keep up with the literature. The student and the young professional are advised to keep 
abreast of developments in these areas not only because they serve as the foundations for practice in the field but also because they serve as entry points to it and are the first basis of challenge to admissibility (that is, with respect to qualifications, competency). In addition, they provide the framework for working in the field, for example, related to dealings with attorneys, referrals, and legal proceedings. Finally, by being expert in these areas, it is easier for practitioners to negotiate the forensic adversarial divide and have one's practice prosper on a long-term basis.

Testing and Diagnosis of Psychological/Psychiatric Injury

Review Psychologists conducting assessments in the area should undertake comprehensive, evidence-based, and impartial assessments using the best scientifically supported instruments for the purposes at hand. They should address response biases and distinguish among symptoms, functional impact, impairments, disorders, and disabilities (as well as apparent effort to improve and to return to work, e.g., on modified part-time duties).

Tests that are reliable and valid are used to supplement other sources of data (interviews, documentation, and so on). In terms of psychometric properties of the tests used frequently in forensic and disability determinations (reliability, validity, sensitivity, specificity), what is the ability of each of the tests to meet Daubert criteria? In these regards, what are the differences in various MMPI tests, such as the basic MMPI-2 and the MMPI-2 RF (Restructured Form; Ben-Porath and Tellegen 2008), as well as other instruments in the field, such as the PAI? For evaluating PTSD, chronic pain, TBI, depression, and related conditions, there are numerous tests, but some of those that are used frequently in practice are due to their traditional use; therefore, they express lacunae in their needed characteristics in dealing with such cases, for example, the populations on which they are normed do not address psychological injury or forensic practice. In addition, they might not possess adequate psychometric properties for such populations (e.g., Beck Depression Inventory II (BDI II; Beck et al. 1996) and MCMI III, respectively). In terms of response bias and malingering, there are (a) stand-alone symptom validity tests, such as the TOMM; (b) embedded scales of response bias, such as in the personality instruments, especially for the MMPI-2; and (c) other instruments for detecting malingering, such as the SIRS.

Kane and Dvoskin (2011) have written a practiceoriented book on forensic assessment in the personal injury context. They extol the psychometric properties of the MMPI-2 and indicate that it meets the Daubert criteria that distinguish good science from poor science in the legal context. The respondent validity scales of the instrument "are especially well suited" for evaluating an open and forthright test-taking attitude, including of possible malingering, although the test results could be ambiguous and interpretations should be based on a comprehensive collection of data. The authors describe the $F$ family, including the Cannot say scale, VRIN, TRIN, L, F (infrequency), $\mathrm{Fb}$ (on the second half of the test), K, S, Fp (Infrequency-Psychopathology), F-K, Other deception, Dissimulation, and the FBS (Lees-Haley et al. 1991).

Kane and Dvoskin supported the utility of the Fp scale, in particular. As for the FBS, which had been added to the MMPI-2 $F$ family stable, the authors reviewed the exchange on its utility in the journal Psychological Injury and Law by Butcher and colleagues and Ben-Porath and colleagues (Butcher et al. 2008; Gass et al. 2010; Williams et al. 2009; compared to Ben-Porath et al. 2009, 2010). Butcher and colleagues and Ben-Porath and colleagues engaged in a heated debate over the value of the FBS scale. For example, the former noted that genuine eatingdisordered patients would be classified as malingerers in $11 \%$ of the sample examined had a cutoff of 29 been used to score the FBS for these patients. The former countered that a study by Greiffenstein et al. (2007) had found that only $1.2 \%$ of respondents without a clear incentive to exaggerate exceeded this cutoff (false positives, $N=1,052$ ). According to Kane and Dvoskin, in his literature review, Rubenzer (2009) found a low false positive rate for the validity of the FBS in non-litigating cases. However, Kane and Dvoskin commented that "the false positive rate remains a concern."

About other tests, Kane and Dvoskin reviewed studies indicating that the false positive rate for the PAI is too elevated. As for the MCMI III, both the articles reviewed by Kane and Dvoskin and Kane and Dvoskin themselves recommended against its use in forensic evaluations to determine response styles. The SIRS was given good standing for this task, but the SIRS-2 (Rogers et al. 2010) was considered lacking supporting evidence, given its recent publication.

Note that the practice guidelines for the forensic evaluation of psychiatric disability have been developed by the American Academy of Psychiatry and Law (Gold et al. 2008). The guidelines are comprehensive, but it should be noted that they give short shrift to the type of psychological testing that distinguishes psychologists in their work in disability determinations (e.g., WAIS-III: Wechsler 1997; MMPI-2, Halsted-Reitan Battery: Reitan and Wolfson 1985). Moreover, psychiatrists are not trained to administer these tests. For this type of evaluation, Gold et al. referred to the AMA Guides (2008) and the DSM's Global Assessment of Functioning (GAF) scale, as well as the Social and Occupational Functioning Assessment Scale (DSM-IV, American Psychiatric Association 1994). The 
latter scale is more directly related to evaluating workrelated impairment and disability compared to the GAF scale; however, it is still an investigational scale. As for evaluating malingering as an alternative explanation in disability determinations, Gold et al. did not mention psychological tests in this regard despite evidence of their efficacy, for example as documented in the next issue of this journal (D. Berry and N. Nelson (Eds.), Special issue on malingering. Psychological Injury and Law, 2011, 4(1)).

Note that another review of assessment for court purposes (Johnstone et al. 2010) also emphasized the utility of the MMPI-2, at least for neuropsychological assessment in the rehabilitation context, but the authors did not mention the SIRS. This illustrates that there is not one compendium that would satisfy all professionals, and in any one particular case, each practitioner is responsible for the choice of the tests used and the justifications for their selection. For the evaluation of PTSD, Rubenzer (2009) emphasized the MMPI-2 and the SIRS, as well as other tests. Rubenzer added that the newer MMPI-2 respondent validity check scales, such as the Response Bias Scale (RBS; Gervais et al. 2007, 2008, 2009a, b; Wygant et al. 2010) and the Henry Heilbronner Index (HHI; Henry et al. 2006), hold great promise, as does the MMPI-2 RF (BenPorath and Tellegen 2008) and its revised respondent validity scales (Gervais et al. 2009a, b). For example, Thomas and Locke (2010) reported a study confirming the strong psychometric properties of the Somatic Complaints Scale (RC1) of the MMPI-2 RF in patients with epilepsy and those with psychogenic non-epileptic seizures. The authors concluded that the scale is well suited for the assessment of somatization (for another study relating the MMPI-2 RF to somatic complaints, see Burchett and Ben-Porath 2010.)

Practice Comment The assessor who uses the MMPI- 2 and the SIRS in conjunction with stand-alone symptom validity tests (SVTs), such as the TOMM or the Word Memory Test (Green 2005), is adopting a test administration strategy that would be acceptable for court purposes in cases of psychological injury. However, newer versions of these tests have come on the market (e.g., the MMPI-2 RF and the SIRS-2), and the assessor should use these in forensic contexts only when their reliability, validity, sensitivity, and specificity have been adequately established so that to the degree possible, the false positive rate is known and is acceptable. Moreover, tests that examine better claimed impossible and related symptoms are needed, as per the test strategy of the SIRS, in the context of psychological injury, as recommended by Young et al. (2007) for pain. For example, would respondents endorse impossible or plausible but inaccurate pain symptoms if a test included them? Would they endorse similar symptoms putatively associated with PTSD, and so on (Rubenzer 2009)?
Butcher (2010) has criticized the development of the MMPI-2 RF. For example, its first factor appears too general and its client validity tests lack appropriate psychometric properties. Rubenzer (2010) indicated that although the SIRS-2 has many improvements, the manual still includes "erroneous and questionable" arguments and statistics. The author concluded that for somatoform conditions, frequently encountered in cases involving psychological injury, "data are virtually non-existent" for the SIRS-2. Until research carefully establishes the value of changes in well-developed and accepted standardized tests used in cases of psychological injury, the court might question the admissibility of testimony involving them.

However, once the tests acquire sufficient study of their psychometric properties by researchers independent of the test makers' research group, the court is more likely to reject admissibility challenges based on a lack of positive evidence related to the Daubert and related criteria. Also, the revised versions of the tests had been undertaken due to perceived inadequacies in the tests from which they emanate and have kept their strengths while minimizing their weaknesses. One strategy might be to use both versions in any one case and distill the information needed from each of them. This is not difficult to do when the items in the two versions of a test remain the same and the scoring procedures simply add on the new information gleaned from the newer version to the original version.

\section{Malingering}

Review Heilbronner et al. (2009) developed a consensus statement on neuropsychological assessment of effort, response bias, and malingering. They distinguished the terms: effort (insufficient, inadequate, poor), response validity, performance validity, response bias, intentional exaggeration, symptom magnification, feigning, secondary gain, malingering, etc. They considered effort level as a continuum, for example, from volitional exaggeration to non-volitional, from meeting internal psychological needs (factitious disorder) to seeking external (e.g., material) reward (malingering). The DSM conception and definition do not represent well malingering compared to current neuropsychological approaches (e.g., Slick et al. 1999). The authors admitted that poor performance on symptom validity indicators could indicate fatigue, transient poor effort, etc. Some of the tests mentioned included: MMPI-2, PAI, P3 (Pain Patient Profile; Tollison and Langley 1995, for pain), and the SIRS. Multiple testing approaches are investigating weighting procedures.

Practice Comment Consensus statements are important state-of-the-art guidelines. They cannot endorse tests and, 
in this case, should have refrained from mentioning any except for the widely used MMPI. For example, the P3 does not have scales that are as good as others. In addition, tests and their manuals undergo revision, such as with the MMPI-2 (Butcher et al. 2001) and PAI (Morey 1991, 2007) manual revisions and the development of the SIRS-2 (Rogers et al. 2010).

Review Larrabee (2008) has developed a statistical procedure to evaluate client symptom validity (malingered neurocognitive dysfunction) over multiple SVTs. Aggregating across multiple SVT failed results increases the probability of detecting the presence of malingering compared to the use of one indicator alone. The Slick et al. (1999) criteria to evaluate the presence of malingering require multiple sources of evidence, such as SVTs. Larrabee (2008) examined the data profiles of litigants with definite malingering contrasted with non-malingering patients having moderate and severe traumatic brain injury. He used chaining of likelihood ratios, and the study demonstrated an increase in probability of malingering when multiple test scores were positive. According to the author, failure on three SVTs demonstrated high probabilities of malingering irrespective of the base rate. The data suggested that attribution of probable malingering is supported even when two SVTs are failed. This suggests modification as well as simplification of the Slick et al. (1999) criteria for malingered neurocognitive dysfunction. Larrabee concluded that calculation of likelihood ratios is a very useful means of depicting the likelihood of a diagnosis of malingering.

Practice Comment The statistical procedure developed by Larrabee (2008) can be used to evaluate the significance of one to several failures over a series of symptom validity tests in assessments. However, in order that it adds incremental validity to assessments, it should be subject to further scientific scrutiny and ongoing research. Moreover, it is highly recommended that assessors consider the full range of possible explanations when there are more failed scores in symptom validity testing. Malingering is difficult to prove directly without implicating evidence, and other explanations need to be ruled out before attributing this motivation to a complainant's presentation and test results (nevertheless, the assessor could use other ways to ascribe doubts about the validity of client presentation in such cases).

An important concern relates to the validity of algorithms such as Larrabee's in multiple symptom validity testing. Ultimately, they are useful to guard against incorrect inferences related to false positives and false negatives. However, the procedures might serve to inflate Type I and Type II errors; for example, they might unduly inflate the significance of one to a few false positives in a series of tests. If practitioners use statistical procedures in their assessments that yield results that defy face validity, common sense, or scientific logic, they risk successful Daubert challenges in court. For example, on the one hand, if a weighting procedure finds that failing only two of seven symptom validity tests or embedded tests of credibility means that the individual is probably malingering, it could be doubtful that triers of fact would buy into the procedure used to arrive at the conclusion. On the other hand, there might be other explanations that apply in such cases (such as a cry for help). Moreover, in presenting evidence in court, practitioners might need to understand the complex statistics involved and how they apply to any case at hand.

Review McGrath et al. (2010) reviewed the literature on response bias as a source of error variance in applied assessment. The 41 investigations that met entry criteria examined response bias indicators as suppressors or moderators of the validity of various substantive psychological indicators. Of the 44 sets of outcomes in the studies, only 12 gave evidence in support of the assumption of the effectiveness of response bias measurement. For any particular area, such as emotional disorder assessment, there were few studies. The authors concluded that for areas with enough studies to examine, the support for the use of bias indicators is weak. The authors noted the dangers of false positives as a result of using these indicators, and their costly effects. Another confound related to different results for minority groups. The authors indicated at one point that the defense of the use of response bias indicators in court could be difficult.

Practice Comment We need careful research on the topic of response bias testing such as in McGrath et al. However, SVTs and other response bias indicators play an important role in psychological injury assessments. The dangers of not using them would be worse than the dangers of using them, for we would be reverting to experts proffering opinion based only on subjective indicators and clinical judgment. One way of adjusting to the difficulties presented by the McGrath et al. study is that psychologists should be mindful of using cutting scores or comparative scores, such as $T$ scores, that allow for too high a rate of false positives.

Research needs to be done on the efficacy of response bias instruments when multiple ones are used in concert. The research needs to involve the populations relevant to civil forensic cases, such as tort action after motor vehicle accidents (MVAs). Factors such as gender, culture, age, degree of physical injury, and disability status should be factored into creating relevant norms.

Review Nelson et al. (2010) conducted a meta-analysis of the FBS, part of the MMPI-2 stable of $F$ tests. They 
analyzed 32 FBS studies that met inclusion criteria, involving a pooled sample of 2,218 overreporting subjects and 3,123 comparison subjects. The meta-analysis found large omnibus effect sizes for the FBS. There were larger effect sizes when participant effort was known to be insufficient and when assessments took place for TBI. The results were considered to offer strong support for the use of the FBS in forensic neuropsychology practice.

Practice Comment The FBS is still a test being researched, and other views on its value are still not excluded (as per the exchange of articles by Butcher and colleagues and Ben-Porath and colleagues in the present journal, described above). Moreover, one could ask questions of the metareview, such as the control groups in the TBI studies used in the analysis, whether the results vary for criminal and civil cases, whether they differ according to injury severity (for mild, moderate, and severe TBI, major depression vs. adjustment disorder, different degrees of physical injury severity according to physical injury scales). Can we find out how a litigating TBI sample would compare with comparable TBIs who are not litigating? Is there a limit to how much one can learn based on simulators? How much do we learn for psychological injuries from studies where the control group is a criminal forensic sample? Also, consider that in the meta-analysis, the $F$ scale "family" did better with PTSD cases.

The Nelson et al. study is one more study that supports the FBS, while there remain many on each side of the issue; more importantly, more research is needed. There are no definitive studies to date. These types of questions do not invalidate the results found, which add a layer of support for the FBS, but they point to limitations and future directions in the research.

It must be kept in mind by practitioners that there is no gold standard in detecting malingering in psychological/ psychiatric injury cases. Moreover, the results of one test procedure, no matter how reliable and valid, should not be the sole basis for considering the presence of malingering. Also, even when evidence points in that direction, it must be incontrovertible, or else different means of conveying one's doubt about the truth value of a complainant's symptoms should be used.

Review In an article in this issue of the journal, Berry and Nelson (2010) decried the lack of change in the most current draft of the DSM-5 with respect to malingering. They found fault with the present DSM approach both on conceptual and empirical grounds. They noted that malingering and related concepts are dimensional in nature, unlike the categorical approach taken by the DSM. They compared other proposals to revise the DSM's approach to malingering. They indicated that attributions of intention, as required by the DSM criteria, are likely to be highly speculative. They recommended that malingering be removed from the DSM-5 and replaced by the concept of Feigned Psychiatric, Physical, and Neuropsychological Symptoms. They recommended multiple strategies for evaluating the presence of feigned symptoms and advised care in minimizing false positives. "Symptom validity tests typically set cutting scores that hold false positive rates to 5-10\%."

Practice Comment One blind reviewer of the article recommended that it should be widely disseminated, including to the DSM-5 draft working group, to increase its impact. The DSM approach to malingering should be revised. It confuses practitioners and can lead to abuses. The DSM-5 draft is being criticized for some of its errors of commission. The Berry and Nelson article point to an error of omission that is not too late to rectify. Practitioners using the DSM criteria of malingering need to tread very carefully. The approach taken by current research, in general, and by Berry and Nelson (2010), in particular, should be acknowledged in court rather than relying on exclusively the DSM-IV.

Overview If the legal and forensic sections of the field of psychological/psychiatric injury and law provide the foundations for working in the area, the boundaries of accepted competency, and what is needed for effective practice in it, the areas of assessment, diagnosis, testing, and malingering provide the basis for effective practice at the client level. The astute assessor will undertake a comprehensive, impartial assessment for court purposes and use state-ofthe-art assessment procedures and instruments that are reliable and valid, and informed by scientific procedures and reasoning. The forensic adversarial legal divide will be especially evident at this stage of practice in psychological/ psychiatric injury and law. There are and will continue to be contentious debate on selected psychological tests, for example. The practitioner cannot rely exclusively on the literature in addressing these debates because often the workers on either side present careful arguments underscored by scientific study. It is the nature of science to proceed by increments and to build on the knowledge base in the field. Practitioners need to follow the exchanges in the literature and be prepared to defend their approach in assessment, test selection, and test interpretation, as well as other aspects of the assessment process in terms of the science behind it. Moreover, they need to be able to address any opposing approach and defend their approach relative to any other in crossexamination. Impeccable knowledge of the science underpinning all aspects of one's assessment is the best manner of dealing with any case and any cross. 


\section{Disability}

Review In terms of disability determinations, mental health practitioners should distinguish among symptoms, impairments, disorders, functional impacts, and disabilities (as well as residual and transferable skills, and ability to return to work, e.g., on modified part-time duties). Psychological assessment of disability in psychological/psychiatric injury needs to consider: the relationship between diagnostic and functional assessment; the role of contextual factors, such as factors that promote illness behavior; and the role of the injured person's approach, such as coping and motivation. It is crucial to address adherence to treatment and efforts to mitigate loss.

There are definitional distinctions to consider-with symptoms and disorders relating to diagnostic concerns, impairments and disabilities relating to functional ones (limitations and restrictions), and handicap relating to perception of impairments and disabilities (both by the person and by others and society).

Goldstein and Naglieri (2009) underscored that the field lacks a universal definition of impairment. Medically, it refers to an adverse level of physical function (significant deviation, loss, or loss of use); psychologically, it refers to functional limitations stemming from a psychological disorder, and in the area of mental retardation, it involves adaptive behavior and intellectual deficit. Moreover, the establishment of objective measurement of impairments remains a task in progress.

Peterson and Paul (2009) described the World Health Organization's Model of Health and Disability (WHO 2001) and their International Classification of Functioning Disability and Health. It avoids diagnostic labels, focuses on function, and emphasizes the interaction of individual and context (e.g., environmental demands and supports for return to work). Therefore, in the WHO approach, disability is contextualized, complex, and coalesces personal and external factors. Part of environmental concerns relate to the availability of benefits for the individual evaluated as disabled. This reinforces the need for comprehensive assessments that include evaluation of possible malingering. At the same time, the assessor needs to recognize that there are losses experienced by the individual and not just opportunity for financial gain (Worzer et al. 2009). In addition, the individual is exposed to a medical, work, insurance, and legal environment that could be distressing, non-cooperative, and exacerbating of psychological effects, including pain experience. Workers in the field are developing scales of perceived injustice related to the disability and compensation process (Franche et al. 2009; Sullivan et al. 2009).

Practice Comment The field is developing increased understanding of the risk factors, flags, and barriers that affect optimal recovery and return to work (Bruns and Disorbio 2011; Bruns and Warren 2011), as well as how to individualize and optimize interventions designed to achieve return to maximal recovery and even return to work. The area of musculoskeletal injury serves as one model in the field because of its rigorous scientific approach to the multivariate prediction of disability and return to work (Schultz 2009; Schultz and Gatchel 2005), and the approach is generalizing to other areas related to psychological injury (PTSD; Wald and Taylor 2009). Practitioners in the area should be knowledgeable of the factors that promote and hinder return to work, as well as the burgeoning research on the topic, given their impact on psychological assessment and treatment in these cases.

\section{The AMA Guides}

Review The 2008 American Medical Association Guides to the Evaluation of Permanent Impairment (Rondinelli et al. 2008) are used widely in assessing impairment and permanent disability. The Guides library includes material on causation analysis, return to work planning, and so on. However, are procedures recommended in the Guides characterized by adequate validity, especially for those chapters important to psychologists (on chronic pain, mental impairment, cognitive impairment, etc.)? The Guides might not possess the required reliability and validity for proper forensic mental health assessment, which presents quagmires.

Leclair et al. (2009) reviewed the quality of the Guides. They noted that the Guides try to balance clinical judgment and science; however, impairment ratings that are included ended up "based largely on consensus and expert opinion" because of insufficient methodology and data permitting scientific assessment of functional loss. The Guides have been improved in some senses in the sixth edition so that Leclair et al. (2009) expect better reliability. However, they indicated that the chapter on "Pain-Related Impairment" is "controversial" because of the subjective nature of pain and because of different theoretical approaches. In terms of the chapter on the "Central and Peripheral Nervous System," Leclair et al. noted that the Guides admit that the ranges for impairment categories assume a "validity that does not exist." As for the chapter on "Mental and Behavioral Disorders," the Guides provide numeric ratings of impairment, and Leclair et al. wrote that "it is important to note that this is a controversial decision..." (p. 69).

The authors added that there are significant flaws and problems associated with the Guides' instrumentation, measurement, statistical analysis, and validity in the tools and methods used in impairment ratings. For example, the Brief Psychiatric Rating Scale (BPRS, Anagnostis et al. 
2004) has not been studied in relation to impairment ratings so that its use is "questionable and ambiguous." The GAF is also used to assign mental and behavioral impairment ratings and its use in this regard "is not based on empiric evidence." Similarly, the PIRS (Overall and Gorham 1962), which is also used in the establishment in impairment ratings, "lacks" empirical evidence in support of its use in rating impairment. Partly to avoid using just one particular scale and its problems, the total impairment for mental and behavior functioning is based on the middle score of the three impairment ratings obtained using the BPRS, GAF, and PIRS. However, Leclair et al. (2009) pointed out that the use of a mean score rather than a median score would have been more effective.

Practice Comment On the one hand, in many jurisdictions, the Guides are legally mandated as the source for impairment ratings and status of permanent impairment. On the other hand, there are sufficient problems with them related to the properties important to mental health professionals, such as validity. This could work against both sides in any adversarial confrontation in court, depending on the outcome of the evaluation process using the Guides for mental health-related impairments. The practitioner presenting evidence in court should clarify the deficiencies in the Guides and know how case law in his or her jurisdiction has dealt with them.

Overview The area of psychological/psychiatric injury involves more than just the assessment and diagnosis of disorders and impairments, or denying their presence, as in the case of attributing presenting symptoms to pre-event vulnerabilities and psychopathologies or to gross exaggeration and malingering. That is, it also concerns determining the degree functional impact and disability being experienced by the complainant, if any, and to what degree the complainant has engaged in attempt to mitigate loss. Note that losses could involve daily roles, such as at work, in childcare, or in education. The assessor needs to undertake a comprehensive assessment of these roles, as well as other activities of daily living. These are important legal questions that require a comprehensive approach in assessment to the same degree as for the establishment of diagnosis and disorder, or their lack. Assessors should function as part of a multidisciplinary team if they lack the competence to address this type of question, or if the case requires this approach. The team should include analysis of residual and transferable skills for the daily roles at issue, the degree to which accommodations and modifications in the daily roles at issue should be implemented, and the projected course in any relevant daily role (e.g., whether the workplace will be accommodative; whether the person is totally disabled and no accommodation can help). The major difficulty in the area is the lack of specific psychological tests that can ascertain each daily role of the person, such as specific work role, and how various impacts related to the event at claim affect them. Often, the assessor must rely on the client's verbal report or that of a third party, such as an employer or teacher. However, one can obtain work or school records, for example, to supplement the latter collateral information. In addition, the test battery administered by the assessor should include tests and scales having embedded client validity checks and symptom validity verification, as with the assessment of disorder and impairment. As much as these instruments can be selected for adequacy of reliability and validity, the review indicates that the same cannot be said for the AMA Guides that often serve in defining whether the profile of disorders, impairments, and disabilities presented by a client meet legal or regulatory thresholds.

\section{Psychological/Psychiatric Injury}

\section{Posttraumatic Stress Disorder}

Review Trauma is a prevalent happening and is associated with the development of acute stress disorder and PTSD. However, only a minority of survivors develops PTSD, and resilience factors help in resistance to the development of PTSD (deRoon-Cassini et al. 2010). For example, in their study, anger reactions and difficulties with coping selfefficacy were associated with poorer trajectories in a sample of participants requiring level 1 trauma care, whereas education served a protective factor.

Recent research on PTSD is questioning the DSM's "A" criterion. Robinson and Larson (2010) studied college students who had experienced only significant stressful life events, only traumatic events, or both types of events. They measured these categories with the Life Events Survey (Ribbe 1996) and the Traumatic Events Screening Inventory (Sarason et al. 1978), respectively. PTSD was measured with the PTSD Checklist-Civilian (Weathers and Ford 1996). As for the results, the three groups expressed similar PTSD profiles. The authors concluded that factors such as loss of job and problems at school could elicit PTSD symptoms as much as traumatic events.

Kubany et al. (2010) examined the A2 criterion of intense fear, helplessness, or horror and found that it might be too broad. Researchers have argued against expanding the types of situations that serve as entry criteria to possible PTSD.

Dohrenwend (2010) has developed a typology of highrisk stressors. He argued that it could help avoid the issue of whether there is bracket creep of the entry criteria to PTSD and whether non-traumatic stressors should be excluded from these criteria. Long and Elhai (2009) also 
explored bracket creep in the A2 criterion, and they admitted to arriving at opposite conclusions despite writing together the article. That authors of an article on the topic cannot agree on the issue illustrates the difficult task of defining PTSD. Similarly, some of the criteria of PTSD lead to further difficulties in dealing with it; for example, McFarlane (2010) examined the issue of delayed PTSD.

The major criteria of PTSD are grouped into three clusters in the DSM, which are intrusive re-experiencing, avoidance/ emotional numbing, and hyperarousal. Contemporary research has suggested four-cluster models. For example, King et al. (1998) have found separate factors for avoidance and numbing. Simms et al. (2002) have found factors related to intrusion, avoidance, dysphoria, and hyperarousal. Naifeh et al. (2010) conducted a statistical analysis of the symptom structure of PTSD in Canadian Veterans. Naifeh et al. (2010) reported data consistent with both of the four-cluster models. Therefore, the classic three-cluster approach to PTSD might need to be addressed in the DSM. The authors also reported comorbidity of PTSD and depression. Therefore, despite its relative infrequency given the multitude of lifelong traumas experienced by the population, PTSD is not a condition that appears in isolation of other disorders.

Frueh et al. (2010) reviewed these and related issues concerning their analysis of the proposed revisions to PTSD in the DSM-5 draft document (American Psychiatric Association 2010). They concurred that (a) bracket creep is weakening the construct; (b) there appears to be four factors in its symptom structure, not three; (c) and comorbidity is an issue. They noted that the draft does now recognize the fourfactor structure in its proposed symptom clusters, but new symptoms have been added, too, and the validity of these additions remain to be determined. First (2010) indicated that if the DSM-5 draft proposal to remove the A(2) criterion (reacting to the event with intense fear, helplessness, or horror) is adopted, it will lead to more opportunity for malingering of PTSD.

In terms of treatment, Powers et al. (2010) conducted a meta-analytic review of prolonged exposure therapy for adults and adolescents experiencing PTSD. They found 13 studies with a total of 675 participants. Prolonged exposure was shown to be effective, even at follow-up. However, it was not shown to be more effective than other treatment modalities, such as cognitive behavioral therapy. The authors argued it could be that all the other treatments compared routinely included exposure components.

The area of psychological injury and law will be transformed as biomarkers are found for the critical psychological/psychiatric disorders in events at claim. For example, Bryant et al. (2010) implicated a marker role for the medial prefrontal cortex during non-conscious processing in PTSD. Engdahl et al. (2010) reported that they classified with a high degree of accuracy PTSD participants and healthy controls using synchronous neural interactions as measured in magneto-encephalography.

The study was limited in its use of war veterans. PTSD was evaluated using standardized clinical procedures. In particular, the study found that cortical miscommunication was evident in the communication of areas in posterior portions of the right hemisphere (temporal, parietal, and/or parieto-occipital) with other areas. The results were evident in the task-free component of their investigational paradigm, and they were similar but attenuated in participants in remission. The former findings imply that the neuronal interactions involved in the results reflect a steady-state condition and are not simply evoked by being in a state of recall or re-experiencing. The latter result indicated that the biomarker still could be evident as therapy proceeds and is efficacious. The authors related the findings to the re-experiencing component of PTSD and posited that the results reflect an involuntary persistent activation of interacting neuronal networks that are involving in consolidation of experiences.

Practice Comment Engdahl et al. concluded that biomarkers will refine constructs of PTSD and other diagnoses. In addition, because they offer "objective indicators of diagnostic status," they will serve to improve treatment. The authors do not address the legal implications per se, but neurolaw is based on the premise that individual biomarkers can specify mental states at issue in individual court cases. The path for finding such markers in PTSD could hinge on findings such as those presented by Engdahl et al. However, until they can provide acceptable accuracy, biomarkers should not be taken as gold standards that replace comprehensive assessments, including of response bias.

As for other legal-related issues, Poyner (2010) described her experience assessing veterans with alleged PTSD for disability. Her upright approach to testing was dismissed and led to her removal from this type of work. Political reasons seemed involved, but at a high financial cost to society. This illustrates that the court is influenced by sociopolitical factors, as are other institutions relevant to the field, especially in contentious areas, such as ongoing wars, for which more liberal approaches to treatment availability might be taken, or wherever financial stakes are involved, for which more conservative approaches to treatment availability might be taken.

\section{Pain}

Review Gatchel et al. (2007) described the biopsychosocial approach to pain experience, which contrasts with the medical model, in particular. Aside from biological factors, social and psychological ones can initiate, exacerbate, or maintain clinical presentation. Pain needs to be understood 
as an individually constructed experience in which factors such as socioeconomic condition, prolonged stress, cognitions (e.g., catastrophizing), emotions (e.g., depression), and behavior (e.g., pain avoidance because of fear) interact with physiologic processes (e.g., heightened neurotransmitter activity, activation in the rostral anterior cingulate cortex) in creating a patient's pain experience. Therapeutically for chronic pain patients, an integrated multidisciplinary approach that includes psychological treatment has been found to be cost-effective.

Schatman and Sullivan (2010) reviewed the literature on affective comorbidities and pain. For example, Beck and Coffey (2007) underscored the importance of chronic pain and PTSD. PTSD has been found to be comorbid with depression (e.g., Ginzburg et al. 2009) and other anxiety disorders (e.g., Brown and McNiff 2009). O'Donnell et al. (2004) presented research on chronic pain being especially comorbid with depression. Carleton et al. (2009) found chronic pain comorbid with generalized anxiety disorder.

Liedl et al. (2010) provided evidence for the mutual maintenance of pain and symptoms of PTSD, consistent with the model of Sharp and Harvey (2001). Sharp and Harvey (2001) had argued that patients with PTSD consider their pain experience as a constant reminder of the triggering event. In this regard, Liedl et al. (2010) found that baseline posttraumatic re-experiencing symptoms were related to the same symptoms at 12 months; moreover, they were mediated by levels of pain at 3 months. Another relevant model is that of Liedl and Knaevelsrud (2008). In their model, re-experiencing leads to a sequence of arousal, avoidance, and muscle tension, driving in a vicious circle pain, further avoidance, and re-experiencing.

Otis et al. (2010) found that PTSD contributed to measures of affective distress in a chronic pain population. These studies vary by subject population, mode of injury and so on, but the pattern is clear that polytrauma often accompanies injury and pain, complicating assessment, diagnosis, treatment, and recovery.

Robinson and O'Brien (2010) argued that pain is multidimensional and includes mediating factors such as negative affect, interpersonal factors, and perception of degree of life control. In terms of negative affect, good predictors of pain include catastrophizing, which has been found to account for up to $31 \%$ of the variance in individual pain ratings and to greater disability (e.g., Keefe et al. 2004). Elevated fear-related beliefs lead to avoidance behavior, exaggerated pain perception, and pain sensitivity, as well as contributing to disability (e.g., Vlaeyen and Linton 2000). In addition, passive coping leads to negative outcomes along these lines compared to active coping and acceptance (e.g., McCracken and Eccleston 2006).

The authors concluded that psychotherapy could help (e.g., cognitive-behavioral). For example, in a meta-analysis,
Hoffman et al. (2007) found that both individual psychological treatment and psychological treatment within a multidisciplinary program were effective in treating patients with chronic low back pain. In addition Chou et al. (2009a, b) found that cognitive and behavioral psychotherapy was effective in treating chronic pain. Poleshuck et al. (2010) found that comorbid depression and chronic pain is responsive to interpersonal psychotherapy.

Schatman and Gatchel (2010) and Howard et al. (2010) underscored that malingering should be addressed from a biopsychosocial perspective. That is, treatment providers should provide counseling that address factors such as symptom exaggeration, fear of re-injury, personality features, etc. (In my treatment plans, sometimes I will include symptom exaggeration as a symptom to address!). These authors also provided evidence that a measure of surface electromyography (comprehensive muscular activity profile; CMAP) can detect objectively respondent effort and not only the physical measures to which it is targeted (range of motion, lumbar, lifting capacity). They concluded that more objective measures such as the one described could help eliminate the misuse and the misdiagnosis of malingering. In addition, Bruns and colleagues (Bruns and Disorbio 2011; Bruns and Warren 2011) have described instruments that could be used in claims of pain and found the Battery for Health Improvement 2 (BHI 2; and the briefer BBHI 2: Bruns and Disorbio 2003; Disorbio and Bruns 2002, respectively) to be instruments that are particularly useful in this context.

Practice Comment Teasell et al. (2010) reviewed the literature in dealing with an evidence-based approach to whiplash injuries. They concluded that the strongest evidence was for acute whiplash-associated disorder. Surprisingly, in this systematic review of the research spanning 1980-2009 and in which half the studies involved randomized control trials, even in the acute phase, the authors reported that the specific intervention is immaterial to the reported improvements in the acute phase, as long as it is not neck immobilization, whether it be "formal physiotherapy, mobilization exercises or simply advice to remain active." In the long term, activity is beneficial, but "more is not necessarily better." Simple advice to remain active is as good for outcome as progressive strength training. The advice should not involve reassurance of good outcome as this might not transpire. The authors ask practitioners to reexamine the classic "hurt vs. harm" concept in that it is too simplistic. Rather than telling patients that recovery is not necessarily interfered with by pain, one should advise that some pain will come with activity and that too much pain "should be avoided." The alteration of this basic canon in dealing with recovery from injury is important for mental health practitioners to know. 
Other findings are that initial severity of the injury predicts outcome, but psychological factors do not. Nevertheless, psychotherapy can help coping. I would add that this includes limiting the exacerbating effects of stress, poor sleep, poor mood, and so on on the pain experience and its effects (note that other classic approaches in the area pain are being challenged for their efficacy. For example, Martelli et al. (2007) described that the "Waddell signs" are no longer considered good indicators of non-organicity or malingering per se).

Research on the use of the major psychological tests in the detection of malingering in cases of pain-related disability claims continues and detection procedures keep improving, although not to the point of providing scales that have the potential of biomarkers to address complainant validity (e.g., Hopwood et al. 2010, on the PAI). A major goal of research in the area should be to ascertain how objective physiological indicators and psychological test procedures can be used in concert to better detect malingering. However, it should always be kept in mind that there are multiple reasons for lack of effort, including the effects of psychological distress occasioned by the pain and its propagating factors, such as job loss, increased relational discord, insurance and litigation pressures, and so on.

Note that Main et al. (2008) described well how medical practitioners who adhere to the medical model could become uncertain when there are no objective correlates of a patient's pain complaints. This can affect subtly how they handle the patients, for example leading to questions about the validity of the pain reported, ignoring or dismissing them, or even considering them signs of malingering, seeking secondary gain, and feigning, or as expressive of psychosis. This attitude might be conveyed just nonverbally, but it leaves the impression with patients that their pain is uniquely all in the mind. The doctor orders tests and, as no medical evidence is found to explain the pain experience, the patients lapse into a vicious circle of despair, mistrust of the medical system, and enhancement of pain behavior.

As for legal-related issues, Schatman and Sullivan (2010) pointed out that about half of US state legislatures have enacted tort reform that aims to reduce noneconomic damages, such as for "pain and suffering." They concluded that this affects the capacity of pain patients to reconstruct meaning in their lives so that the tort reforms are "ethically suspect." Young (2010a) opined that the DSM-5 draft changes for pain disorder would complicate getting both treatment and redress in court because it will become a subclass of complex somatic symptom disorder.

\section{Traumatic Brain Injury}

Review The article examines this topic only briefly, given the space provided. Sbordone and Ruff (2010) examined when it is appropriate to diagnose PTSD when there is TBI (e.g., because of difficulties with loss of consciousness). Sbordone (2010) queried the ecological validity of tests of executive function, neurobehavioral symptoms, and frontal lobe function. Ruff and Jamora (2009) examined the myths involving mTBI. They concluded that it exists in a miserable minority and that it can endure as a post-concussive condition due to non-central effects, such as might happen after an MVA. Gironda et al. (2009) found that polytrauma involving TBI, pain, and PTSD was much more complicated to treat and requires an effective integrated program, including cognitive behavioral components.

De Guise et al. (2010) examined over 2 weeks the clinical profile of patients with complicated (e.g., positive cerebral imaging) and uncomplicated mTBI, including for neurological signs, neuropsychological performance, and self-reported post-concussive symptoms. The latter group reported more post-concussive symptoms, and the two groups appeared equally affected otherwise at the neuropsychological level, with many in both groups returning to work after 2 months on average. However, the former group evidenced greater neurosensory signs. These complicated results indicate that individuals with mTBI should be examined for neurosensory and other neurological symptoms, as well as receive scan screens, in the acute phase. In the absence of these data, both causal mechanisms in complicated cases and ensuing complications in all cases might not be discovered.

It should be noted that cognitive effects could derive in cases of psychological injury even when there is no TBI per se. The compounding effects of experiencing pain, depression, anxiety, and stress, as well as poor sleep, fatigue, medication use, and substance use, could contribute to significant cognitive impairments that require appropriate assessment and treatment despite the absence of a traumatic brain injury. Young et al. (2007; see the section by Nicholson and Martelli) have reviewed research showing that the cognitive effects of factors such as these can exacerbate and serve to maintain cognitive effects from events at claim in cases of mild TBI even after the timeline for the dissipation of pathophysiological effects involved in the TBI. Recent research on the cognitive effects of depression, anxiety, and pain include, respectively, McClintock et al. (2010), Gordeev (2008), and Ji et al. (2010).

Schultz (2010) analyzed the proposed changes to the DSM-V related to TBI, as described by the working group involved, and found multiple difficulties. The diagnosis of neurocognitive disorder will have two types, mild and severe, and moderate degrees will fall into the mild class. Moreover, the literature reviewed by the working group did not especially consider the studies on TBI. In an effort to treat Alzheimer's and other conditions in a uniform manner, the validity of the recommendations is an issue, and if 
implemented, the revisions will present difficulties both to clinicians and forensic examiners.

Practice Comment Much of the developments in the field of psychological/psychiatric injury and law have taken place in neuropsychology. The stakes are high in brain damage cases, and the value of detection of malingering is elevated. This area is responsible for the development of good symptom validity testing, certain scanning procedures, focused neurocognitive testing, neurolaw, diagnostic categories and syndromes, and ecologically valid approaches to assessment and treatment. Practitioners in mental health and law should try to keep abreast of the advances in this area, as well as the controversies.

In terms of the legal arena, Richards and Kirk (2010) offered a tutorial on TBI for attorneys. This is the first article of its type to integrate child and adult neuropsychology for court purposes. It presented relevant epidemiological data, clarified ambiguous terminology, reviewed best practices in assessment and diagnosis, and considered moderating variables that might influence outcome, as well as factors in causality.

\section{Other Psychological Injury Conditions}

Review Duckworth (2008) reviewed the literature to show that pain becomes more entrenched when there are comorbidities, as often happens in motor vehicle collisions (e.g., pain and PTSD; Duckworth and Iezzi 2005; Palyo and Beck 2005). Norman et al. (2008) studied the relationship of trauma symptoms and other conditions in patients admitted to a trauma center. Pain reported in the first $48 \mathrm{~h}$ after injury was associated with an increased risk of posttraumatic stress disorder, even after controlling for relevant risk factors post-injury. Other predictive variables were the amount of pain at the time of hospitalization and peri-injury dissociation.

Depression and generalized anxiety disorder are among the possible consequences of events at claim, such as motor vehicle collisions (e.g., Duckworth and Iezzi 2010; Laugharne et al. 2010), along with substance abuse disorders. When patients have a lower grade difficulty in adapting psychologically to an MVA, an adjustment disorder might be diagnosed. When traumatic symptoms are limited to a targeted fear, such as driving a car, a specific phobia might be diagnosed.

Kendall-Tackett (2010) has documented the pernicious role played by depression, anger, and PTSD in inflammation and effects on health. With injury, pro-inflammatory cytokines are released and, along with other factors such as an increase in cortisol response, act to increase the risk for depression (e.g., Frasure-Smith and Lespérance 2005), hostility (Smith et al. 2007), and PTSD (Sareen et al. 2007). Long-term consequences of these emotions might include coronary heart disease, pain conditions, and impaired wound healing. Kendall Tackett concluded that when depression, anger, and PTSD are comorbid, they compound in their negative health effects. Psychotherapy might work in reducing these ill effects by reducing inflammation.

Aside from evaluating disorders involving psychological injuries (or their lack, as in malingering), practitioners in the field need to evaluate the full psychological presentation of the individual. In this regard, assessment in psychological injury cases should address preexisting psychopathology. In addition, evaluation for the presence of personality disorders is considered cardinal in this field. These types of factors might help explain complainant presentation in full, consistent with the concept of the "crumbling" skull case. Or, factors such as personality disorder might be exacerbated by the event at claim, as in the "thin skull" case (see Young 2007). However, to what degree are personality disorders defined reliably and validly in the DSM, and how are they approached in the DSM-5 draft?

Livesley (2010) indicated that the proposed changes in the DSM-5 draft to the DSM-IV personality disorder section are major. For example, it reduces the number of disorders from ten to five (keeping: antisocial, avoidant, borderline, obsessive-compulsive, and schizotypal). However, these disorders are different in their content and structure compared to their predecessors in the DSM-IV. Notably, they are defined in terms of prototypes, and the clinician is asked to indicate the degree of match of patient to type. Livesley argued that both in terms of underlying theoretical and empirical bases, the major changes in the DSM-5 draft for PD are not explicated. Clinicians might find these changes without clinical utility; it could be harder for their patients to get treatment, and it could be harder to have portions of evidence related to PD admitted to court.

Practice Comment The role of stress in psychological/ psychiatric injury cases is pernicious and pervasive, cutting across diagnoses and disorders. Gatchel et al. (2007) reviewed Melzack's (2005) model that pain is represented by a body-self in the neuromatrix and can be aggravated by effects on the hypothalamic-pituitary adrenal (HPA) axis, such as through the production of cortisol. Chronic stress can lead to the breakdown of muscle, bone, and neural tissue, as well as impairment of tissue repair, leading to (augmented) pain experience.

Concurrent stressors, such as job loss after an injury and the litigation process, can exacerbate a patient's presenting complaints. Gatchel and colleagues (e.g., Howard et al. 2010; Worzer et al. 2009) referred to secondary losses in 
these regards, as opposed to secondary gains. The concept of compensation neurosis, for example, that a settlement cures the pain, has been refuted in the research on the topic (Duckworth 2008; Margoshes and Webster 2000; Mason et al. 2006; Mayou et al. 2002).

Related to the legal front, I would add that in an unspecified proportion of cases, unconscious wishes for maximal settlement might serve to propagate the pain beyond its expected course and intensity. That is, in these cases, years later, at settlement negotiation conclusions, monetary compensation might not cure but factors such as partial conscious malingering, or even unconscious exaggeration of symptoms by unseemly unconscious wants over the years in the patient's mind, would be the reason! Note that absent evidence, this type of logic should not be trotted out indiscriminately for all patients expressing pain conditions.

Overview The practitioner must not only possess the general practice and nomothetic, population-level knowledge in the field of psychological/psychiatric injury and law to function effectively in it but also the ability to ascertain effectively the presence or absence of relevant diagnoses, disorders, and disabilities of individual clients based on the idiographic data collected in assessment. This task is complicated by the contentious nature of the core diagnoses in the area-PTSD, TBI, and chronic pain. Moreover, other diagnoses that might apply, such as involving depression and anxiety, could bemore difficult to relate to the event at claim. The stress that manifests after the event, serving to propagate its psychological/psychiatric effects, might reflect antecedent vulnerabilities that can explain fully the presenting profile. Therefore, even when one can diagnose a core psychological/psychiatric or related injury, the disorder at issue might not be actionable ormight be easily dismissed in court as actionable. Also, the assessment tools in the field for specific psychological injuries need to have their reliability and validity established as much as any others in the field. For example, the prominent instruments used to assess specifically pain, PTSD, and intellectual performance in mild TBI typically do not include embedded client validity scales, rendering the assessment task more difficult for specific core psychological/psychiatric injuries.

The practitioner in this field not only has to be able to disambiguate valid from invalid or questionable presentations but also, if they are valid, (a) which psychiatric diagnosis or comorbid diagnoses best encapsulate them, (b) their validity or relevance, and (c) what are their relative origins in pre-event, event-related, and post-event factors. Moreover, the assessor needs to know the scientific literature on treatment for these various conditions in order to (a) recommend efficacious treatment and intervention plans; (b) formulate the prognosis, should the client demonstrate compliance with the latter; and (c) help estimate future care costs to maintain gains, to accommodate the individual to permanent impairments and disabilities, if that applies, and so on.

Guidelines and Treatment

\section{Guidelines}

Review The Ontario Psychological Association Auto Task Force (Smith and OPA Task Force 2010) produced comprehensive guidelines for evaluation and treating psychological injuries. They reviewed the research before making their recommendations. They indicated the prevalence of the disorders involved and the monetary costs to society. The increased persistence of pain and distress in polytrauma was considered a complicating factor, as was preexisting trauma. They examined subsyndromal conditions and auxiliary stressors, such as litigation stress. Their review of recent research on treatment of psychological injuries supported the use of cognitive behavior therapy. A dismantling study had even been undertaken to determine which components and in what combination work best for PTSD (Bryant et al. 2008). They argued against a manualized approach to therapy because the research involved generally considers simpler cases, such as one disorder being present. They suggested that treatment plans should be individualized and in steps, but they do give normative guidelines. They listed barriers to recovery and complicating factors.

Bruns et al. (2010) described "biopsychosocial laws," or medical-related treatment guidelines for worker's compensation cases that are taking a more comprehensive direction. The system adopted by the state of Colorado exemplifies this new approach to reducing costs and increasing efficacy in dealing with work-related pain and injury. The approach contrasts to the traditional medical model, and its evidence base gives it promise. It will lead to changes in how cases are adjudicated in court and related venues. The particular guidelines that they review for pain and injury include the following: the American College of Occupational and Environmental Medicine's Practice Guidelines (ACOEM 2008), the Work Loss Data Institute's Official Disability Guidelines (Work Loss Data Institute 2008), the Medical Disability Advisor Disability Duration Guidelines (Reed Group 2009), and the Colorado Medical Treatment Guidelines (Colorado Division of Workers' Compensation 2007). The authors maintained that diagnosis should not be equated with functional change. Assessments should be comprehensive and examine functional capacities as well as symptom complaints.

Some of the mentioned treatment guidelines address comorbid psychological and psychosocial factors in addi- 
tion to physical concerns (ACOEM 2008; Colorado Division of Worker Compensation 2007). Other treatment guidelines consider separately psychological and physical concerns, an approach that is considered less reliable and valid (Reed Group 2009; Work Loss Data Institute 2008). As an example, the Colorado guidelines recommend psychological evaluations for chronic pain and after various surgeries. For chronic pain, up to 44 treatment sessions are recommended. The authors concluded that contemporary models of disability view disabilities as a complex of biological, psychological, and social aspects and not just physical and medical ones alone (Pledger 2003; Tate and Pledger 2003).

Gelenberg et al. (2010) developed practice guidelines for the treatment of patients experiencing major depressive disorder. They examined not only psychopharmacology but also psychotherapy and the combination of the two approaches. On a short-term acute basis, various psychotherapies were found to be effective, including cognitive behavioral therapy. For long-term treatment, cognitive behavioral therapy and interpersonal psychotherapy were shown to have lasting benefits after treatment terminated (Dobson et al. 2008; Frank et al. 2007; Vittengl et al. 2007). Different studies on different types of depressed populations using different psychotherapies confirm the value of cognitive behavioral therapy, but also indicate that in some cases, its behavioral component is most efficacious. As well, the value of pharmacotherapy in the treatment of chronic depression has been supported in the research. The results for psychodynamic psychotherapy are mixed, so it is difficult to reach conclusions. As for combined psychopharmacology and psychotherapy treatments, this approach seems especially effective for severe depression.

Canadian guidelines for depression indicate that psychotherapy can be effective along with other interventions (Parikh et al. 2009; Patten et al. 2009). For example, the authors reviewed 85 randomized control trials (RCTs) that provided empirical support for the efficacy of cognitive behavioral therapy in treating mild to moderate major depressive disorder, with the therapy being as effective as antidepressant medication.

Practice Comment Work in the area of psychological/ psychiatric injury involves third party and government payors who publish treatment guidelines, as do professional organizations and journals in the area. The scientific bases for the guidelines need to be clearly explicated, as does the cost effectiveness, time frame for successful outcome, and so on, of the recommended treatment guidelines. However, the evidence-supported treatment approach in the guidelines needs to be based on quality science, and also the treatments recommended by treatment providers should end up considering the individual as much as the normative suggestions for it to be effective. Cookie cutter approaches to treatment that limit individual variation should be avoided, but, at the same time, license to continue treatment when there is no evidence that it is helping, maintaining gains, or stopping degeneration should be avoided.

\section{Treatment}

Review Other work has supported the use of psychotherapy to treat depression (Drapeau 2010; Goldfreid 2010). Fournier and DeRubeis $(2010 \mathrm{a}, \mathrm{b})$ identified predictors of response to treatments for depressive disorders, which indicated that short-term cognitive therapy is even more effective than antidepressant medication for those who are married, unemployed, without a personality disorder, and experiencing a large number of events in their lives. They discussed matching strategies across individuals and different treatment strategies. Lazar (2010) reviewed the literature about the cost effectiveness of psychotherapy in treating depression. It should be noted that the research reviewed included interpersonal psychotherapy and other approaches aside from cognitive behavioral therapy. Also, cost effectiveness was not simply defined monetarily.

Driessen and Hollon (2010) confirmed the efficacy of cognitive behavior therapy for mood disorders. They noted that cognitive behavior therapy reduced relapses and recurrence in chronic or recurrent disorders at a rate equivalent to keeping patients on medications. Olatunji et al. (2010) found that cognitive behavior therapy has also been shown to be effective in the treatment of anxiety (e.g., specific phobia, PTSD). Allen and Woolfolk (2010) have shown that cognitive behavior therapy has been found effective for somatoform disorder. However, to date, there have been no controlled trials examining its efficacy for pain disorders.

All of these articles review the effectiveness of cognitive behavioral therapies and call for continued research to understand the change mechanisms involved and for dismantling studies to understand which components of the therapy are most effective and how they mediate the change process. Hofmann et al. (2010) pointed out that "new wave" cognitive behavioral therapies essentially consist of the basic components in traditional cognitive behavior therapy.

Practice Comment Zinbarg et al. (2010) concluded the special issue and these series of articles in the Psychiatry Clinics of North America by indicating that cognitive behavioral therapy is being integrated with other approaches, such as the biological, the cognitive, the information processing, and the systemic, as well as motivational interviewing and strength-based approaches. 
They predicted that this will further enhance the position of cognitive behavior therapy as a dominant approach to mental healthcare work, partly because of its "ready" accountability and cost effectiveness.

This should alert practitioners to events developing in the field, but is cognitive behavior therapy the most effective in all circumstances with patients manifesting psychological injuries, and is the evidence-based approach the only way to test its comparative efficacy? For the first question, the reader is referred to Young (2008a) who described an integrated approach to treating psychological injuries, one based on ten major components of the person, including the physical, in a whole person and whole system approach.

About the second point, the practice guidelines reviewed, such as described by Gelenberg et al. (2010) for treating depression, attempt to be evidence-based. However, Wachtel (2010) indicated that evidence-based or empirically supported research on treatment practices (EST) is founded on the gold standard of randomized control trials. Usually, this type of research involves a study of a single diagnostic category and usually involves manualization of treatment. However, he pointed out that the medical research using RCTs employs a double-blind methodology in which both the patient and doctor are unaware of which drug is being prescribed. In psychotherapy research, it is virtually impossible to use a double-blind methodology. About his second major concern, some therapies lend themselves to manualization more than others, essentially excluding from empirical validation and support those that cannot be well manualized. Wachtel (2010) concluded that "this is not a championing of science; it is an abdication of science."

The unfortunate consequence of the EST approach on research on psychotherapy is that it can be used without extensive training or by personnel who are expensive to pay. Wachtel (2010) referred to this approach to mental healthcare as the "Walmart" approach. He also pointed out that effective therapy especially involves the establishment of a good therapeutic relationship and the general skillfulness of the therapist (also see Castonguay and Beutler 2006; Martelli et al. 2008). Beutler (2010) emphasized that the common principles involved in therapeutic change related to client characteristics, the therapeutic relationship, and therapeutic procedures.

Wachtel (2010) also listed the unique principles for treating depression-related disorders. The common principles of therapeutic change account for much of the effectiveness of therapy. He argued that the EST movement is based on problematic or faulty assumptions and that psychotherapy nevertheless can be investigated empirically on a sound basis. For example, effective research in the area can be achieved using correlational studies, process-outcome studies, naturalistic research, and quasi-experimental studies using meticulous methods controlling for potential confounds.
Another practice comment relates to treating the psychologically injured from an ecologically valid perspective that acknowledges their frequent polytrauma. The difficulty in treating polytrauma obtains because of mutual maintenance factors (e.g., Liedl et al. 2010, for pain and PTSD). Vicious circles develop that exacerbate reciprocally the conditions, e.g., through hyperarousal and hypersensitization (McFarlane 2010). Treatment plans need to be sufficiently cognizant of the increased need for psychotherapy in such cases. Moreover, they have to be based on the individual differences that clients express, for example in terms of their ongoing symptoms and environmental (e.g., family) context, and their exacerbatory factors, such as those that precede, accompany, and follow the event at claim.

In addition, clients need to be monitored for compliance and effort to mitigate losses. Also, treatment plans might be longer for cases with preexisting exacerbatory factors. However, this represents a double-edged sword legally because although the rehabilitation might be more complicated because survivors need to be taken as they are found, the damages awarded might be lessened to only that portion of the damage for which the insurer is liable. Evaluations undertaken for needs of treatment plan formulation should be based on an impartial stance, as in the case of forensic evaluations.

Overview Guidelines for the treatment of psychological injuries are in the beginning stage of development. They require extensive literature searches and integrations of the literature, with focus on evidence-based treatment. However, the latter is not easy to define in psychology and psychiatry, and the results are not always clear in the research. Much about therapy effectiveness depends on general characteristics in treatment, such as (a) therapist variables, (b) establishing rapport, (c) fit of therapist and client, and (d) client willingness to cooperate with treatment requirements. Therapists need to address effort to mitigate loss, but there is no gold standard in assessing this factor on an ongoing basis in therapy. Instruments could be used that include scales on therapy readiness as part of the initial assessment, but they cannot be administered routinely in therapy. Manualized treatment approaches and guidelines recommend fixed amounts of therapy for various conditions, but comorbidities and other complications render each case different. At the same time, normative expectations should not be dismissed lightly and the astute therapist takes them into consideration.

\section{Causality}

Review The legal tests of causality include substantial cause, minimal cause, material cause, and the but-for-test. The latter two tests are given prominence legally (e.g., 
Young 2010b). Note that although the concept of a substantial contribution of a component of a causal nexus is a common one, recently, the concept has been criticized, and it is explicitly rejected and abandoned in the final draft of the Third Restatement of Torts (American Law Institute 2007). It is considered both too strict and too lenient, depending on how it is used, and its use has strayed from its original intent. The argument made is that as long as a factor is a material contributor or factor beyond the de minimus, insubstantial, theoretical, infinitesimal, trivial, or negligible range, it should be considered part of the causal nexus, and there is no reason to give it the added threshold of having to be "substantial." In cases of joint responsibility in material causation, it is best to apportion causation among the factors and adjust the subsequent liability awards for damages.

Young (2007, 2008b, 2010b) has developed a body of work pertaining to causality in psychological injury and law. In the 2007 chapter, he noted mostly the factors to consider in establishing causality in the individual case. For example, are there pre-event psychological vulnerabilities that can explain complainant presentation in part (the thin skull rule), or in full (the crumbling skull rule)? Has the assessment been comprehensive enough to establish scientifically which interpretation about causality connection is most appropriate and can be expressed with sufficient certainty (e.g., more than likely) for court purposes? In the $2008 \mathrm{~b}$ article, in particular for the legal area, he presented a synthetic model of causality determination that is based on common sense principles and scenarios, as much as anything else. It asks to consider both product and process in causality.

In addition, at the practice level, Young took to task the AMA guides (Rondinelli et al. 2008) approach to causality, pointing out its problems involved with validity, in particular. In the most recent article (Young 2010b), Young examined the ecological pressures that influence causality determinations, including the pressures of the adversarial divide and the role of legal standards (see Fig. 1). He presented work (Haack 2008) that analyzed the scientific testimony proffered in Daubert according to its scientific validity. Paradoxically, the evidence presented in this famous case that led to the Daubert ruling against poor or junk science was not as scientific or impartial as originally maintained by experts called by Dow.

The figure indicates the layers of influence that determine definition and tests of causality and causation in cases involving either individual or mass action torts. The first inner circle concerns immediate influence of the
Fig. 1 The psycho-ecological model of legal causality

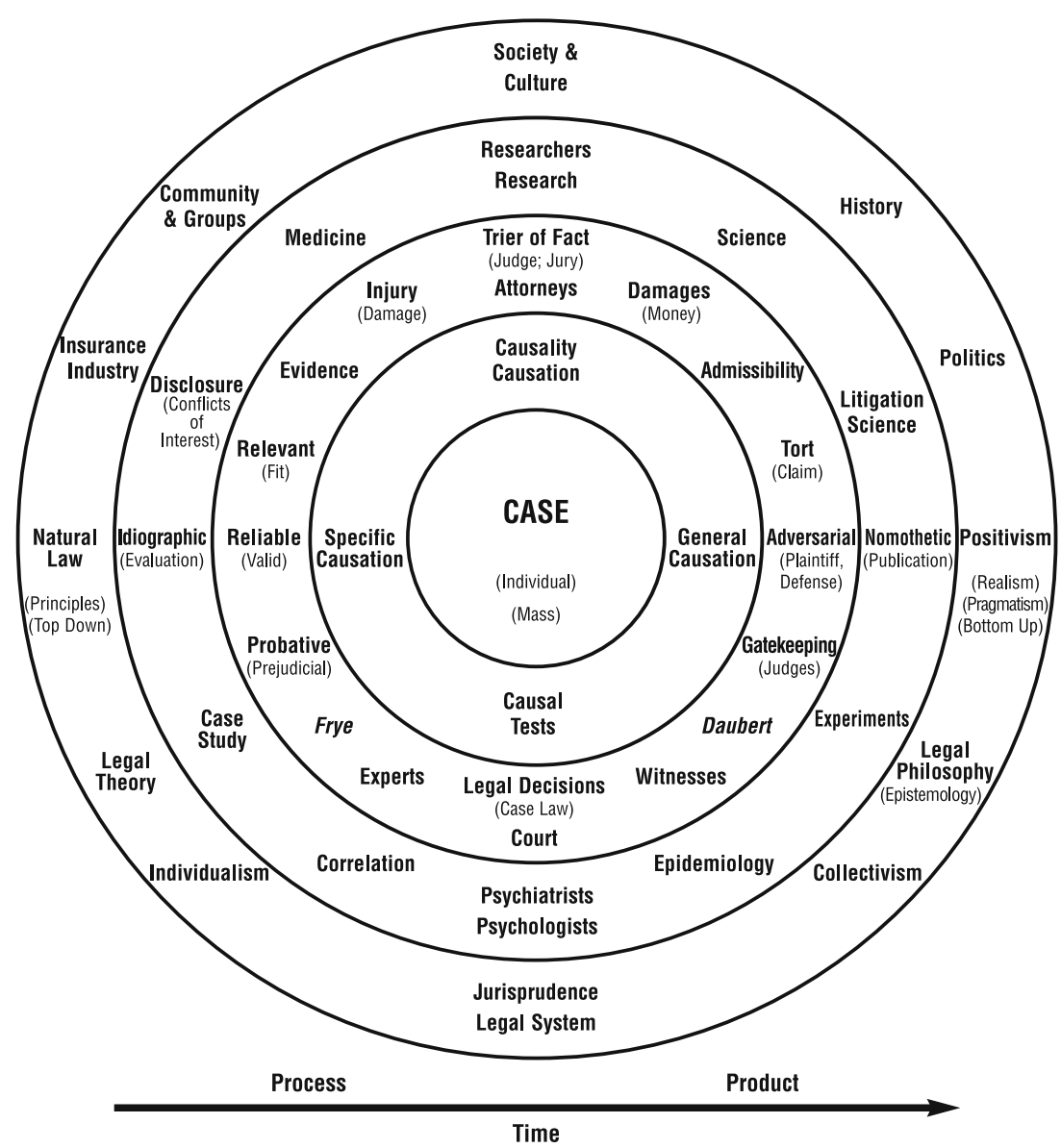


court system in relation to the claim at hand due to the event at issue. Psychologists need to be attuned to the adversarial divide and the pressures that it exerts on them to engage in partial and incomplete assessments of injured and ill parties for the benefit of the plaintiff or defense side. Is the scientific evidence presented by the expert sufficiently reliable and valid to meet admissibility standards of good compared to poor or junk science and help the court, according to extant criteria of good science described in Daubert (1993), in particular?

The second inner circle presents factors that can adversely impact good science, such as conflicts of interest and litigation science and how they affect individual evaluations and population-level publications. Is the research undertaken for court or presented to court biased, with factors hidden, such as links to industry, and are individual evaluations conducted with biased science serving to justify partial conclusions? The outer circle examines wider factors related to society, politics, industry, and so on, and philosophical and theoretical approaches to the construction of law.

The model serves to illustrate that a wide range of variables influences laws about causality in tort and similar actions. In constructing laws, pragmatic adjustments are needed, but ones that do not devalue the harmed, impaired, and disabled survivor in an event at claim and their rights to fair treatment, compensation, and justice. The model attempts to present an integrated model of causality that addresses process (e.g., good law) and product (e.g., good psychological evaluation). It is labeled "psycho-ecological" to emphasize the role of context in constructing law and the role of psychological factors in all major actors and agents involved, from the individual complainant to the professionals involved to institutions such as the insurance industry.

Practice Comment An important issue to consider in practice related to psychological/psychiatric injury is causality - to what extent has the event at issue contributed materially to the presenting complaints? Usually, causality is multifactorial (Young 2007, 2008c). Good psychological practice in arriving at justifiable conclusions in a case at hand should be based on the biopsychosocial model, with prudent forensic elements interposed. There are many threats to validity in evaluating causality, including malingering. Moreover, all pre-event, event-related, and postevent developments, both related to the event and independent of it, need to be considered. In terms of pre-event factors, examples include ascertaining the relative influence of preexisting psychological vulnerabilities, psychopathology, or personality disorders. The psychologist is addressing the proverbial "thin" skull in apportioning causation, or whether pre-event factors have rendered the individual vulnerable so that the event has an effect beyond what might be expected otherwise. Also, the complainant has the obligation to mitigate losses, participate in therapy, comply with treatment requests, and so on. These factors need to be considered in presenting evidence to court so that conclusions on causality reach standards of admissible good science.

Models

Review Much of Young's work is aimed at developing overarching models that can serve the field, given its disparate nature, the multiple areas it considers, its relatively nascent status as a coalescing field, and the absence of integrating models. Often, Young presents these models as integrating graphics.

The field of psychological injury and law requires practitioners to see the big picture, which includes the adversarial divide. In addition, it also includes insurance pressures to minimize claims and possible client malingering to maximize them (see Fig. 1). Science constitutes a crucial mediator in resolving these extremes, when used well by psychologists. In the end, causality in this type of work is about establishing the event at claim as a material contribution to the effects generated.

The table that follows the figure in the article also emphasizes the multifactorial nature of causality. Young (2008d) constructed tables that summarize 100 factors involved in the biological, social, and psychological influences in somatization, and the tables are summarized here (see Table 1). The table illustrates how difficult it is to understand the origins of physical symptoms and the precursors involved in pain conditions deriving from an event at claim.

The figure after the somatization table indicates the complexity in the pain experience (see Fig. 2). Not only are there biopsychosocial models to understand pain, but the concept of dynamical pain attractors has been applied to understand the way chronic pain becomes deeply ingrained and how it is hard to treat, given the confluence of multiple factors in its origins. At the same time, there are health attractors as well as illness attractors that are posited to develop, and therapy can be construed as attempts at shifting the attractor basins involved.

The next model illustrates a combined biopsychosocialforensic model that is predominant in the field (see Fig. 3). In conducting assessments in the area, one obtains comprehensively all the data needed to make an informed scientifically based decision. Then causation can be apportioned to preexisting, event and peri-event, and postevent factors, as well as auxiliary factors. Is there a material contribution from the event? Is the client a thin-skull case 
Table 1 Biopsychosocial model of somatization (from Young 2008b)

Type of influence

Biological factors

Innate or early

General

Specific

Medical

Medical, personal history

Medical, family history

Medical, ongoing

Sensorial effects

Sensitization

Sensation

Secondary effects

Neurovegetative

Stress factors

Neurobiological

Neuronal

Neurological

Lobes, regions

Systemic

Functional

Psychological factors

Basic psychological processes

Arousal

Perceptual

Attention, concentration

Learning

Cognition

Cognitive, basic

Cognitive, amplification

Cognitive, advanced

Cognitive, executive

Cognitive, medical

Cognitive, networks

\section{Affect}

Emotional, internalizing

Emotional, other

Mood

Behavior

Behavioral, passivity

Behavioral, activity

Behavioral, dependence

Behavioral, dominance

Coping and resilience

Coping

Resilience

Self factors

Self-regulation
Specific factors

Genetic; congenital

Sex/gender; age

Acute, phasic; chronic, tonic

Modeling of illness behavior, dependence;

Modeling of disability, compensation

Acute (e.g., virus); active chronic, tonic

Peripheral; central

Proprioceptive; kinesthetic

Sleep problems; nutrition

Autonomic, HPA axis, cortisol;

Immune system dysfunction

Circuitry; connectivity

Cortical; limbic, lower

Frontal, etc.; amygdala, etc.

Plasticity; inhibition, activation

CNS excitability; hypersensitivity

Lowered perceptual threshold; faulty signal sensitivity, filtering Symptom vigilance

Classical; operant

Memory, expectation

Symptom exaggeration; catastrophizing

Somatic attribution; disease conviction

Organization, persistence; systemic, pervasive

Disbelieve negative results; believe doctors/systems do not listen

Schemas; narratives

Depression; anxiety

Fear of symptoms; anger (e.g., at the system)

General distress; demoralization

Avoidance; deconditioning

No distraction; no tasks

Illness behavior; helplessness

Need reassurance; doctor shopping

Emotional, dependent; fight or flight, withdrawal

Vulnerable, threat sensitivity; diatheses, distress intolerance

Affective; cognitive 
Table 1 (continued)

\begin{tabular}{|c|c|}
\hline Type of influence & Specific factors \\
\hline Image & Body; self \\
\hline \multicolumn{2}{|l|}{ Personality, risk, and psychopathology } \\
\hline Personality & Neuroticism; negative affectivity \\
\hline Psychiatric disorder & Clinical disorder; personality disorder \\
\hline At risk behavior & Addictions, dependence; legal, police \\
\hline \multicolumn{2}{|l|}{ Ecological factors } \\
\hline \multicolumn{2}{|l|}{ Social } \\
\hline Historical & Trauma, stresses, adversity, conflicts; losses (parental, supports, resources) \\
\hline Parental attachment style & Preoccupied; dismissing \\
\hline Role strain/stress & School, work; family, care giving \\
\hline Interpersonal conflict & Familial, relational, peers; work, community \\
\hline Inadequate support & Social, familial; professional \\
\hline Overly solicitous support & Social, familial; professional \\
\hline \multicolumn{2}{|l|}{ Cultural } \\
\hline Socioeconomic status & Poverty, job loss; community, neighborhood \\
\hline Attitudes in culture & Emotional control; sanction physical symptom expression \\
\hline \multicolumn{2}{|l|}{ Contextual } \\
\hline Medical & Diagnostic uncertainty; lack of explanation, guidance \\
\hline Treating professionals & Skepticism; provider profits from treatment \\
\hline Disability role & Expect benefits, compensation; avoid unpleasant roles, responsibilities \\
\hline Insurance & Contest benefits; Arrange repeated insurance examinations \\
\hline Social-cultural/political-economic & Pharmaceutical marketing; public health service cutbacks \\
\hline
\end{tabular}

or even a crumbling one, with everything in current presentation explained by pre-event factors? Or, is the client doing well and has experienced adequate coping, traumatic growth, and integration. Finally, factors such as exaggeration, feigning, crying out for help, and malingering need to be tested and considered in arriving at these conclusions.

The final table in the article presents key terms related to causality and causation from the fields of law, medicine, psychology, and philosophy (see Table 2). These fields sometimes have different meanings for the same term, different terms for the same meaning, and different sets of terms not considered by the other fields. This creates confusions for practitioners in the area. Moreover, psychologists need to be aware of the legal tests and thresholds in the field in order to address them effectively. For example: What do attorneys mean when they refer to the term of reliability, the same as psychologists? Are "damages" for the former the same as "damage" for the latter? Does permanent impairment mean no chance of improvement at all, or that further psychotherapy is not needed?

Practice Comment Practitioners in the field are faced with the daunting task of keeping up with about ten specialty areas in the field of psychological/psychiatric injury and law. They risk focusing on a few major ones most directly related to their practice. However, they should develop currency in all of them and have access to the material that integrates the material for them. Moreover, they need to be aware of the grander psychological themes in behavior as the risk is that they become too narrowly focused on legal issues and cases and forget their original interests in understanding the field, or of understanding behavior and its causes and determinants. Models such as the ones presented are aimed at helping practitioners see the big picture in these ways.

Overview Practicing in the field of psychological/psychiatric injury and law could lead to tunnel vision, both in terms of (a) idiographically, not viewing the client as a whole person living in context, and (b) nomothetically, not seeing the big picture of the field. For the idiographic level, this refers to conducting assessment and therapy that evaluate the person as a whole individual having (1) more than disorders and impairments but also disabilities, if any, in relevant, individualized daily roles and (2) the degree to which the presenting symptom profile is valid or inconsistent and reflective of malingering or other response biases. For the nomothetic level, it refers functioning from the framework of general models that integrate the biopsy- 
Complex Adaptive Systems

Dynamical Pain Attractors

\section{Course of Pain Experience}

Biosychosocial Processes

Neuromatrix/ Body-Self
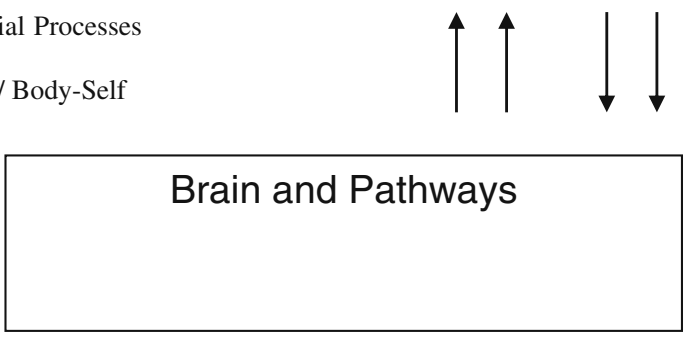

Central Psychological Processes

Gate Control Mechanism

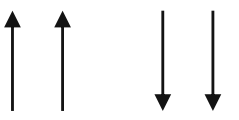

Spinal Cord

Nociception

Peripheral systems

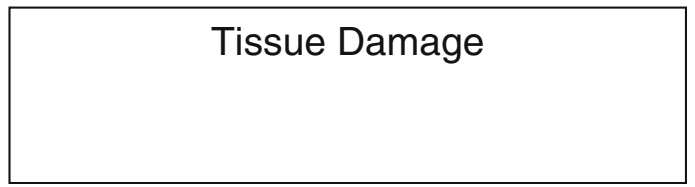

Fig. 2 Pain complexity (from Young et al. 2007)

chosocial and forensic perspectives, in particular. The person reflects a complex expression of biological, psychosocial, and legal factors. Also, the models should be developmental to the degree possible. In using global models such as these, the assessor conducting individual assessments should investigate this latter parameter, for example, with respect to early determinants of somatization tendencies. The causal factors considered should also include extra-individual variables related to institutional pressures, such as (a) insurance and litigation distress, on the one hand, and (b) signs of attorney coaching and the like, on the other hand.

\section{Multicultural and Gender Considerations}

Review Psychological injuries (e.g., PTSD, chronic pain, TBI) vary with gender and multicultural status, and psychologists need to know the literature on these variations. The court expects psychologists to proffer evidence that considers such factors. In assessments on psychological injury, psychologists need to use reliable and valid measures, which include ones that consider gender and multicultural factors. In their interpretations and conclusions, they need to be sensitive to cultural and gender factors. Gender and multicultural considerations are an essential part of forensic assessment. Some tests have specific scale differences depending on gender. Individuals from different cultural backgrounds might tend to respond differently to assessment instruments and processes. Preexisting disability is an essential aspect to consider in injured parties.

Hunter and Schmidt (2010) examined anxiety and psychopathology in African American adults from a sociocultural perspective. The literature indicated lower rates of anxiety disorders in African American adults compared to European Americans. They found lower rates of generalized anxiety disorder, for example, and comparable rates of PTSD, with lower rates of panic disorder (Pole et al. 2008). Mental health assessors and treatment providers should be aware of the full scope of their sociocultural model. It includes learning history and contextual variables, such as sociocultural beliefs and attitudes related to awareness of racism, stigma of mental health, and so on. These factors can lead to cultural mistrust, underreporting of symptoms, avoidance of treatment, and corresponding increased attention to somatic symptoms. This process promotes catastrophic interpretations and understanding of somatic symptoms as physical illness.

Similarly, for other minority groups, new models are being developed. Castillo and Caver (2009) discussed health disparities in light of acculturation in Mexican Americans in rehabilitation for disability. Their model is bilinear, involving assimilation and enculturation, with biculturalism as a useful option in cultural adaptation. Also, when individuals of Mexican American heritage adopt extreme stereotypes [machismo (in males) and marianismo (in females)], this affects negatively the rehabilitation process.

Practice Comment Because of space limitation, I could give only a basic introduction to the issue of cultural, racial, and other group and population considerations in assessing psychological injuries and treating individuals with them. The DSM does describe some disorders or syndromes unique to particular cultures. However, this effort should be expanded. Young and Johnson (2010) have indicated how the changes in the DSM-5 draft with respect to PTSD are amenable to consideration of minority, cultural, racial, and ethnic factors. However, they concluded that there is much work to be done in this regard not only for PTSD but also for the DSM, in general. Moreover, in forensic and disability assessment, practitioners need to be aware of possible effects of assessor-assessee cultural, racial, gender, and related 
Fig. 3 Integrated biopsychosocial/forensic model in psychological injury and law (from Young 2008c)

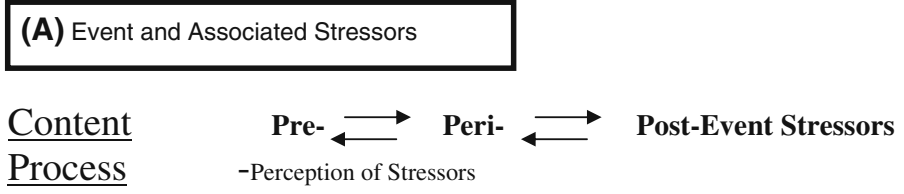

\begin{tabular}{|c|c|}
\hline \multicolumn{2}{|c|}{ (B) Acts on Lifespan System } \\
\hline \multirow{3}{*}{ Content } & $\begin{array}{l}\text {-Risk Factors } \\
\text {-Developmental Stage or Level }\end{array}$ \\
\hline & $\begin{array}{l}\text {-Ongoing Ecological Adaptation and Ecological Alteration in Daily Life } \\
\text { (Equilibrium) } \\
\text {-Adaptation to Family, Work, School, Institutions, Neighborhood, Community }\end{array}$ \\
\hline & -Health \\
\hline
\end{tabular}

\begin{tabular}{llll} 
& Bio & Psycho & Social \\
\cline { 2 - 3 } Process & Genetic & Individual Differences & Environment \\
Physiological & Personal Attributes & Experience \\
Organic & Organismic & Significant Others \\
Chromosomes & Coping & Culture \\
Innate/Prepared & Personality & Place \\
& Evolutionary & Self/Ego & Ecology/Niche \\
& Hereditary & Hope/Optimism & History/Political Influences \\
& Maturational & Motivation & Context/Milieu \\
& Nature & Need/Desire & Nurture
\end{tabular}

(C) Areas Vulnerable in Outcome/Functionality

$\begin{array}{ll}\text { Content } & \begin{array}{l}\text {-Body-Brain-Injury-Pain-Trauma } \\ \text {-Behavior-Actions-Activity-Life Roles-Quality of Life } \\ \text {-Emotions-Affect-Feelings-Mood-Self-Regulation } \\ \text {-Cognition-Thinking-Alertness-Mind-Reason } \\ \text {-Complicating/Confounding Factors-Symptom } \\ \text {-Exacerbation/Minimization-Malingering }\end{array} \\ \text { Process } & \text { Integrative } \longrightarrow \text { (Dis)equilibrium }\end{array}$

differences. There are also gender differences; however, these might not be as straightforward as they seem. For example, although women are at a higher risk for PTSD, they are also more liable to posttraumatic growth (Tolin and Foa 2006; Gupta and Bonanno 2010; respectively).

\section{Diagnostic and Statistical Manual of Mental Disorders-V}

Review The diagnostic manual used in the field is undergoing revision (DSM-IV-TR), and to what extent are current diagnostic categories pertaining to psychological injury valid in the DSM-IV? Frances (2010a, b, c, d) has been a vocal critic of the DSM-5 proposals. In particular, he addressed the implications for forensic practice. For example, criteria could be confusing and new diagnoses could likely become "forensic and insurability disasters."

Indeed, one can even ask whether the major categories of psychological/psychiatric injury are valid entities and should be included in the DSM. For example, some argue that (a) pain disorder should not be in the DSM because pain is more physiological than psychological (e.g.,
Melzack and Katz 2006); (b) PTSD is a category that is overdiagnosed for court purposes and should not even be in the DSM (e.g., McNally 2003); and (c) mild TBI cannot lead to persistent post-concussive syndrome with pathophysiological underpinnings because mild TBI typically resolves early after onset (e.g., McCrea 2008).

Some of the changes that might be taking place in the DSM$\mathrm{V}$ might have a major impact on forensic and disability testing, assessment, and practice. Once criteria are changed for PTSD, for example, all tests that are based on prior criteria will have to be revised and undergo extensive research on their psychometric properties. As for pain disorder, the working group involved will be making it an optional specifier of a somatoform disorder, if plans are adopted (complex somatic symptom disorder, pain disorder). What will be the effects of clearly labeling every pain patient having psychological problems as ones with somatic disorders, in particular with pain as a specifier only? There will be numerous other changes that will affect our area, such as with conditions related to TBI and personality disorder, collapsing the first three axes together, adding new categories without sufficient empirical support, etc. (see the special topic in the present issue, entitled the DSM-5 
Table 2 Key terms related to causality and causation (from Young and Shore 2007)

\begin{tabular}{ll}
\hline Term & Meaning (simplified) \\
\hline Key terms related to causality and causation in law \\
Concurrent & Joint \\
Contributing & Secondary \\
Immediate & Most recent \\
Intervening & Added \\
Joint & Multiple \\
Material & Part of joint \\
Proximate & Dominant (direct) \\
Remote & Initial, too far removed \\
Superseding & Replacing dominant \\
Key terms related to causality and causation in medicine \\
Component & Part of multiple \\
Exacerbation & Worsening \\
Exciting & Direct \\
Immediate & Beginning, initial \\
Predisposing & Susceptible \\
Primary & Principle \\
Remote & Predisposing, secondary \\
Secondary & Not principal \\
Ultimate & Remote \\
Key terms related to causality and causation in psychology \\
Catalytic & Facilitative \\
Latent & Delayed \\
Maintaining & Current \\
Mediating & Intervening \\
Multiple & Multifactorial \\
Original & Remote, initial \\
Remote & \\
Triggering & Initial \\
\hline &
\end{tabular}

Draft and Forensic Psychiatry and Psychology, Psychological Injury and Law, 2010, 3(4)).

Practice Comment Once the DSM-5 draft is converted to the official DSM-V in a few years' time, practitioners in the area of psychological/psychiatric injury and law will be facing major challenges in the field, whether they are mental health workers or attorneys. The standard diagnostic manual is changing in many ways, and although its stated goal is to be informed by research, there are other forces at work in the changes being proposed. Moreover, the draft has not been vetted for the forensic implications of its wording, given that even a seemingly minor aspect can have serious forensic consequences (Frances 2010d). Practitioners are advised to tread carefully in using the future DSM-5 in their cases in psychological/psychiatric injury. As with the care needed in arriving at professional opinions about psychological tests used, for example concerning their psychometric properties, the practitioner needs to adopt the same care about the reliability and validity of the diagnostic categories ascribed to individuals.

Overview Some of the greatest challenges in working in the field of psychological/psychiatric injury and law involve the individual differences that are inherent in the psychology of people and the lack of diagnostic tools that consider them. For example, often there is insufficient research on developmental and cross-cultural research pertaining to psychological/psychiatric injury. The same lack is evidenced in the diagnostic manuals in the field, such as the DSM-IV-TR, particularly for some diagnoses, including those relevant to our field. The DSM is being revised, but the present review of core psychological injuries indicates that much research is needed to obtain sufficient understanding of their origins, manifestation, and best treatment options. The same applies to many diagnoses offered in the DSM, and the new ones being proposed or those being revised in the DSM-5 draft could become beset by controversy that affects the whole field, as other articles in this issue indicate. Practitioners in psychological/psychiatric injury and law need to use the DSM at multiple points in their work. However, it should be scrutinized with the same scientific rigor called for in all aspects of their work.

\section{Summary}

This article has reviewed the current literature in all major areas of psychological/psychiatric injury and law and has provided practice commentaries for each of them. A succinct summary would emphasize (a) the need to adopt a scientific, impartial stance in working in the area, (b) the need to arrive at scientifically justified conclusions in assessments for court and related purposes, and (c) the need to maintain a middle-of-the-road approach relative to the forensic adversarial divide in order to ensure practice longevity. The practitioner should admit what one knows about science and the case at hand and what one does not know, for example, about prognosis in a case or the degree of certainty about conclusions proffered. However, the practitioner should strive to learn all that there is to know scientifically that is applicable to the case at hand and for court purposes.

\section{Recommendations for Psychological Injury and Law}

To conclude the article, I present recommendations to solidify the gains made in the field and to assure best 
practice policies in it. The literature reviews that have been conducted in each of the major areas of the field have led to practice comments related to them. In the following, I provide a more integrated perspective. In particular, I emphasize the need for cross-discipline communication and collaboration. In addition, I suggest that best practices in the field ask that practitioners engage in peer communication and collaboration.

\section{Integrated Field}

The field of psychological/psychiatric injury and law is one that is coalescing around the need for scientifically informed mental health practice and for knowledge of legal and related matters that interdigitate with it. It is composed of about ten major areas, each of them requiring both leading-edge work by researchers and state-of-the-art knowledge by practitioners. Moreover, the research needs to be interdisciplinary, for example involving psychologists and attorneys, psychologists and psychiatrists, and psychologists and neuroscientists. Also, the practice in the area needs to be cross-discipline, for example in multidisciplinary teams.

It is recommended that leaders in the field understand and work toward the integration required in the field to provide focus to researchers, practitioners, educators, and students. They should encourage journal and monograph publications that facilitate and promote such integration, as with the present journal and its parent society. Finally, professionals at any level of experience in the area should be offered continuing education workshops on topics relevant to psychological/psychiatric injury and law, such as the ones given by our society members in the last few years.

\section{Integrated Study}

Graduate students face a daunting task learning the diverse areas involved in the field, as well as effective practice in it. The area requires multiple knowledge bases, such as brainbehavior-body relationships, neuropsychology, trauma work, forensic psychology, and the law related to evidence, tort, worker compensation, and other legal-related venues. Also, the student needs to acquire skills in assessment, testing, diagnosis, therapy, working as part of teams, dealing with families, and in report writing and testimony. The present journal and the increasing publications in the area, both in other journals and in books, whether written by Psychological Injury and Law board members or others, should be consulted and used as appropriate.

In terms of recommendations, leaders in the field should encourage educators of graduate students interested in this area of psychology to acquire the needed expertise before they graduate, preferably in dedicated programs with all these elements in psychological/psychiatric injury and law. Graduate departments and law schools should be encouraged to create dedicated programs in the area, facilitating and expanding professional practice in it. In addition, young professionals in either psychology or law should be able to form sections or even divisions in state and provincial associations dedicated to practice in the area.

\section{Integrated Research}

Multiple examples of research needed in the field can be offered, and many have been provided in the text of the article. In the following, I consider broader issues in research. First, psychologists and attorneys should be investigating the pressures in the system that work for or against justice, fairness, truth, and equality. They should be working with the multiple stakeholders in the system, such as insurers and workers compensation, as well as professional associations, to elucidate and describe in publications aimed to the various professions workable laws, rules, and regulations governing the area that are based on good law and good science. There are practical considerations, as well, to consider, such as ways of limiting fraudulent claims and professional practice that borders on the unethical if not illegal.

About recommendations, leaders in the field should encourage granting agencies and universities to provide funding for grant proposals that meet standards of good science in the area and that can contribute, in particular, to understanding psychological injury and how it persists or how it is alleviated. In addition, related to the legal front, granting agencies should be encouraged to consider the types of collaborations mentioned above, as well as any research that can explain and help dampen the adversarial divide in the field. In the end, the best way of dealing with the divide is to have researchers conduct impeccable middle-of-the-road research that lets the chips fall where they might on controversial issues, for example as exemplified by the approach taken in PIL.

\section{Integrated Practice}

Work in the area of psychological/psychiatric injury and law, by definition, involves teamwork. On the one hand, the mental health professional needs excellent knowledge of the workings of the court and the requirements expected of him or her, whether trained as a forensic psychologist or other type of professional dealing with psychological/ psychiatric injury. On the other hand, the mental health professional needs to work with other members of interdisciplinary teams, whether in terms of multidisciplinary assessment or multidisciplinary rehabilitation. This type of interdisciplinary work sets apart professionals in this 
area, aside from the special competencies that they need, for example related to forensic-related psychological testing.

As for recommendations, state and provincial regulatory boards, along with other regulatory boards, should be encouraged to specify qualifications needed to practice in the area and seek to certify practitioners as competent in the area, for example that they have the necessary education, training, and experience (without asking them to do another graduate degree beyond their doctorate). Placements during studies should be particular to the field, such as in law practices dealing with these type of cases and psychology or psychiatric practices dealing with them and involved in interdisciplinary collaboration along the lines described.

\section{Integrated Assessment}

Psychologists who assess individuals for effects of events at claim, such as in tort action or workers compensation, should be conducting comprehensive, impartial, and scientifically informed assessments. They consider all the data gathered before arriving at conclusions and consider alternate explanations and why they do not apply to the case at hand. They integrate interview data, psychological tests scores, review of prior documentation and records, including in other reports and clinical notes, and they watch for nonverbal cues and mental status observations in the assessment, not relying uniquely on verbal responses to questions. They consider complainant response biases, including that of possible malingering. At the same time, they consider their own biases, such as confirmatory bias.

Their impartial scientific attitude should apply even when they are clinicians seeking treatment plan authorization in their reports, for their duty is not only to the client but to the highest standards of the profession, including integrity, impartiality, and adhering to guidelines and regulations requiring such objectivity. This does not lessen a caring attitude in relation to the client. In contrast, it heightens it, and it is not compromised in acting fairly for the system and profession as well as the client.

It is recommended that leaders in the field encourage psychological test companies to promote positive practices in test construction and usage in the areas of psychological injury and to support research on the standardization of relevant instruments on populations involved in psychological injury. Tests need to be chosen for their fit with the purposes of the assessment, but if the standardization population of any one instrument does not include persons with the types of issues of concern to the field, they are harder to justify and defend in court as appropriate ones for the case at hand, or the conclusions reached by using them could be considered inadmissible.
Integrated Treatment

Clients who have sustained psychological injuries usually have physical and psychological symptoms acting in concert, complicating treatment. They express symptoms of polytrauma, for example manifesting symptoms subsyndromally or in full with respect to chronic pain, trauma reactions, and perhaps traumatic brain injury. Even without TBI, they express cognitive symptoms due to the cumulative effects of stress, depression, anxiety, and pain experience. Even without a physical injury, there could be physical symptoms, such as from headaches, somatization reactions, elevated stress reactions involving cortisol and hyperarousal, effects of depression in the brain, and so on. The treating professional must be aware of brain-behavior-body interactions and use an integrated therapy this way. In addition, there are family and context considerations that lead to further systemic approaches to the client's needs.

With respect to recommendations, practitioners, educators, and students should learn, teach, and use integrated therapeutic and intervention techniques that are individually tailored to client needs and symptoms along the lines indicated. Leaders in the field should promote this biopsychosocial approach to treatment, but it should be tempered by forensic considerations, such as monitoring compliance with obligation to mitigate losses. In addition, state and provincial treatment guidelines in cases of psychological injury and law should be built from this integrated perspective, describing a common framework for treating the conditions that is partly based on evidence-based or evidence-supported research on practice, but allowing for other treatment approaches and for tailoring and matching for individual differences, group differences, and values.

\section{Integrated Model Building}

Any field of scientific endeavor is only as good as its theorizing and the empirical work deriving from it. The area of psychological/psychiatric injury and law needs to keep building integrated models, such as the combined biopsychosocial-forensic one that marks the present work. The model should branch out to better include interdisciplinary considerations in neuroscience, psychoneuroimmunology, neuropsychology, neuropsychiatry, neurophysiatry, neurolaw, and other brain/behavior-based disciplines. In addition, it needs to become especially developmental, not only in terms of children and adolescents but also in terms of the different phases of adulthood and the elderly. The models must become increasingly cultural and gender-sensitive, examining proximal and distal influences on client presentation of different populations. 
In terms of recommendations in model building, the field should continue on its present path, integrating what each of its areas has to offer and arriving at models that respect their divergence and unity. We look forward to the area becoming a central one in psychology, contributing to understanding psychopathology, personality, assessment, brain-behavior-body relationships, stress, psychological injuries, practice matters, and treatment in a crossdisciplinary and integrated way.

\section{Conclusions}

The literature review and commentary undertaken in this article can help the young professional and graduate student learn how to function effectively in the field of psychological/ psychiatric injury and law. It provides an overview of all the major areas in the field - from law and forensics to assessment and malingering; to psychological/psychiatric injuries and disabilities, and their treatment or required interventions; and, in general, to models and recommendations for the field. The article constitutes a state-of-the-art review that sets the stage for the practitioner and graduate student to keep up with this fast growing field by indicating its major areas and how they relate to each other, as well as by describing recent developments and contentious issues in them and how to navigate them.

Acknowledgments Many thanks to David Berry and Dan Bruns for their helpful comments on portions of the text and to five anonymous reviewers for same. Eric Drogin and Andrew Kane served as action editors for this paper.

Conflicts of Interest The author has obtained most of his attorney referrals and psycholegal referrals from plaintiff rather than defense attorneys and assessment companies.

Disclaimer The opinions expressed represent those of the author and not the journal board or society board.

\section{References}

Ackerman, M. J. (Ed.) (2010). Essentials of forensic psychological assessment (2nd ed.). New York: Wiley.

Allen, L. A., \& Woolfolk, R. L. (2010). Cognitive behavioral therapy for somatoform disorders. Psychiatry Clinics of North America, 33, 579-593.

ACOEM (American College of Occupational and Environmental Medicine). (2008). Occupational medicine practice guidelines (2nd ed.). Beverly Farms: OEM.

American Law Institute. (2007). Restatement of the law third torts: Liability for physical and emotional harm (tentative draft no. 5). Philadelphia: American Law Institute.

American Psychiatric Association. (1994). Diagnostic and statistical manual of mental disorders (4th ed.). Washington: American Psychiatric Association.
American Psychiatric Association. (2000). Diagnostic and statistical manual of mental disorders: Text revision (4th ed.). Washington: American Psychiatric Association.

American Psychiatric Association (2010). Proposed draft revisions to DSM disorders and criteria. Arlington, VA: American Psychiatric Association. Retrieved from http://www.dsm5.org/Pages/Default. aspx.

American Psychological Association. (2002). Ethical principles of psychologists and code of conduct. The American Psychologist, 57, 1060-1073.

Anagnostis, C., Gatchel, R. J., \& Mayer, T. G. (2004). The pain disability questionnaire: A new psychometrically sound measure for chronic musculoskeletal disorders. Spine, 29, 2290-2302.

Beck, J. G., \& Coffey, S. F. (2007). Assessment and treatment of PTSD after a motor vehicle collision: Empirical findings and clinical observations. Professional Psychology: Research and Practice, 38, 629-639.

Beck, A. T., Steer, R. A., \& Brown, G. K. (1996). Manual for the beck depression inventory - II (2nd ed.). San Antonio: Psychological Corporation.

Ben-Porath, Y. S., \& Tellegen, A. (2008). MMPI-2 RF (Minnesota Multiphasic Personality Inventory-2 Restructured Form). Minneapolis: University of Minnesota Press and Pearson Assessment Systems.

Ben-Porath, Y. S., Greve, K. W., Bianchini, K. J., \& Kaufmann, P. M. (2009). The MMPI-2 symptom validity scale (FBS) is an empirically-validated measure of overreporting in personal injury litigants and claimants: Reply to Butcher et al. (2008). Psychological Injury and Law, 2, 62-85.

Ben-Porath, Y. S., Greve, K. W., Bianchini, K. J., \& Kaufmann, P. M. (2010). The MMPI-2 symptom validity scale (FBS) is an empirically-validated measure of over-reporting in personal injury litigants and claimants: Reply to William et al. (2009). Psychological Injury and Law, 3, 77-80.

Berry, D. T. R., \& Nelson, N. W. (2010). DSM-5 and malingering: A modest proposal. Psychological Injury and Law, 4, 295-303. doi:10.1007/s12207-9087-7

Beutler, L. E. (2010). Therapeutic factors in mood disorders. Integrating Science and Practice, 1, 10-13.

Briere, J. (2001). Detailed assessment of posttraumatic stress: Professional manual. Odessa: Psychological Assessment Resources.

Brodsky, S. (2004). Coping with cross-examination and other pathways to effective testimony. Washington: American Psychological Association.

Brown, T. A., \& McNiff, J. (2009). Specificity of autonomic arousal to DSM-IV panic disorder and posttraumatic stress disorder. Behaviour Research and Therapy, 47, 487-493.

Bruns, D., \& Disorbio, J. M. (2003). Battery for health improvement 2 manual. Minneapolis: Pearson Assessment Systems.

Bruns, D., \& Disorbio, J. M. (2011). The psychological assessment of patients with chronic pain. In T. R. Deer (Ed.), AAPM textbook of pain medicine. New York: Springer Science + Business Media.

Bruns, D., \& Warren, P. A. (2011). Assessment of psychosocial contributions to disability. In P. A. Warren (Ed.), Handbook of behavioral health disability: Innovations in prevention and management (pp. 73-104). New York: Springer Science + Business Media.

Bruns, D., Müller, K., \& Warren, P. A. (2010). A review of evidencebased biosychosocial laws governing the treatment of pain and injury. Psychology Injury and Law, 3, 169-181.

Bryant, R. A., Moulds, M. L., Guthrie, R. M., Dang, S. T., Mastrodomenico, J., Nixon, R. D. V., et al. (2008). A randomized controlled trial of exposure therapy and cognitive restructuring for posttraumatic stress disorder. Journal of Consulting and Clinical Psychology, 76, 695-703.

Bryant, R. A., Kemp, A., Felmingham, K., Liddell, B., Olivieri, G., Peduto, A., et al. (2010). Simulating emotional response in 
posttraumatic stress disorder: An fMRI study. Psychological Injury and Law, 3, 111-117.

Burchett, D. L., \& Ben-Porath, Y. S. (2010). The impact of overreporting on MMPI-2-RF substantive scale score validity. Assessment, 17, 497-516.

Butcher, J. N. (2010). Personality assessment from the nineteenth to the earth twenty-first century: Past achievements and contemporary challenges. Annual Review of Psychology, 6, 1-20.

Butcher, J. N., Dahlstrom, W. G., Graham, J. R., Tellegen, A., \& Kaemmer, B. (1989). Manual for the restandardized Minnesota multiphasic personality inventory: MMPI-2. An interpretive guide. Minneapolis: University of Minnesota Press.

Butcher, J. N., Graham, J. R., Ben-Porath, Y. S., Tellegen, A., Dahlstrom, W. G., \& Kaemmer, G. (2001). Minnesota multiphasic personality inventory-2: Manual for administration and scoring (2nd ed.). Minneapolis: University of Minnesota Press.

Butcher, J. N., Gass, C. S., Cumella, E., Kally, Z., \& Williams, C. L. (2008). Potential for bias in MMPI-2 assessments using the Fake Bad Scale (FBS). Psychological Injury and Law, 1, 191-209.

Carleton, R. N., Abrams, M. P., Asmundson, G. J., Anthony, M. M., \& McCabe, R. E. (2009). Pain-related anxiety and anxiety sensitivity across anxiety and depressive disorders. Journal of Anxiety Disorders, 23, 791-798.

Castillo, L. G., \& Caver, K. A. (2009). Expanding the concept of acculturation in Mexican American rehabilitation psychology research and practice. Rehabilitation Psychology, 54, 351-362.

Castonguay, L. G., \& Beutler, L. E. (Eds.). (2006). Principles of therapeutic change that work. New York: Oxford University Press.

Chou, R., Atlas, S. J., Stanos, S. P., \& Roenquist, R. W. (2009). Nonsurgical interventional therapies for low back pain: A review of the evidence for an American Pain Society clinical practice guideline. Spine, 34, 1078-1093.

Chou, R., Fanicullo, G. J., Fine, P. G., Adler, J. A., Ballantyne, J. C., Davies, P., et al. (2009). Clinical guidelines for the use of chronic opioid therapy in chronic noncancer pain. The Journal of Pain, 10, 113-130.

Colorado Division of Worker Compensation (2007). Rule 17, Exhibit 9: Chronic pain disorder medical treatment guidelines. Retrieved 25 July 2010 from http://www.coworkforce.com/dwc/ Rules/Rules\%202007/New\%20MTG/EX 9 Chronic Pain.pdf.

Committee on the Revision of the Specialty Guidelines for Forensic Psychology. (2010). Specialty guidelines for forensic psychology (5th draft). Washington: American Psychological Association.

Daubert v. Merrell Dow Pharmaceuticals, Inc. 113S. Ct. 2786 (1993).

Daubert v. Merrell Dow Pharmaceuticals, Inc. 43F. 3d 1311 (9th Cir.1995).

de Guise, E., Lepage, J. F., Tinawi, S., LeBlanc, J., Dagher, J., Lamoureux, J., et al. (2010). Comprehensive clinical picture of patients with complicated vs. uncomplicated mild traumatic brain injury. The Clinical Neuropsychologist, 24, 1113-1130.

deRoon-Cassini, T. A., Mancini, A. D., Rusch, M. D., \& Bonanno, G. A. (2010). Psychopathology and resilience following traumatic injury: A latent growth mixture model analysis. Rehabilitation Psychology, 55, 1-11.

Disorbio, J. M., \& Bruns, D. (2002). Brief battery for health improvement 2 manual. Minneapolis: Pearson Assessment Systems.

Dobson, K. S., Hollon, S. D., Dimidjian, S., Schamling, K. B., Kohlenberg, R. J., Gallop, R. J., et al. (2008). Randomized trail for behavioral activation, cognitive therapy, and antidepressant medication in the prevention of relapse and recurrence in major depression. Journal of Consulting and Clinical Psychology, 76, 468-477.

Dohrenwend, B. P. (2010). Toward a typology of high-risk major stressful events and situations in posttraumatic stress disorder and related psychopathology. Psychological Injury and Law, 3, 8999.

Drapeau, M. (2010). Treatment of depression: A societal choice. Integrating Science and Practice, 1, 3-4.

Driessen, E., \& Hollon, S. D. (2010). Cognitive behavioral therapy for mood disorders: Efficacy, moderators and mediators. Psychiatry Clinics of North America, 33, 537-555.

Duckworth, M. P. (2008). Psychological conditions associated with motor vehicle collisions. In M. P. Duckworth, T. Iezzi, \& W. T. O'Donohue (Eds.), Motor vehicle collisions: Medical, psychosocial, and legal consequences (pp. 311-344). New York: Elsevier.

Duckworth, M. P., \& Iezzi, T. (2005). Chronic pain and posttraumatic stress symptoms in litigating motor vehicle accident victims. The Clinical Journal of Pain, 21, 251-261.

Duckworth, M. P., \& Iezzi, T. (2010). Physical injuries, pain, and psychological trauma: Pathways to disability. Psychology Injury and Law, 3, 241-253.

Engdahl, B., Leuthold, A. C., Tan, H.-R. M., Lewis, S. M., Winskowski, A. M., Dikel, T. N., et al. (2010). Post-traumatic stress disorder: A right temporal lobe syndrome? Journal of Neural Engineering, 7, 1-8.

Faust, D., Grimm, P. W., Ahern, D. C., \& Sokolik, M. (2010). The admissibility of behavioral science evidence in the courtroom: The translation of legal to scientific concepts and back. Annual Review of Clinical Psychology, 6, 49-77.

Finch, M., Guthrie, C., \& Henderson, C. (2008). Expert testimony on psychological injury: Procedural and evidentiary issues. Psychological Injury and Law, 1, 20-35.

First, M. B. (2010). The PTSD stressor criterion as a barrier to malingering: DSM-5 draft commentaries. Psychological Injury and Law, 3, 255-270.

Fournier, J. C., \& DeRubeis, R. J. (2010a). For whom do antidepressant medications work? Integrating Science and Practice, 1, 22-24.

Fournier, J. C., \& DeRubeis, R. J. (2010b). Predictors of response to treatments for depression. Integrating Science and Practice, 1, 24-25.

Frances, A. (2010a). Opening Pandora's box: The 19 worst suggestions for DSM5. Psychiatric Times, February 11. Retrieved from http://www.psychiatrictimes.com/dsm/content/article/10168/ 1522341.

Frances, A. (2010b). DSM5 temper dysregulation good intentions, bad solution. Psychiatric Times, April 2. Retrieved from http://www. psychiatrictimes.com/display/article/10168/1556809.

Frances, A. (2010c). Normality is an endangered species: Psychiatric fads and overdiagnosis. Psychiatric Times, July 6. Retrieved from http://www.psychiatrictimes.com/dsm-5/content/article/10168/ 1598676.

Frances, A. (2010d). The forensic risks of DSM-V and how to avoid them. Journal of the American Academy of Psychiatry, 38, 1114.

Franche, R.-L., Severin, C. N., Lee, H., Hogg-Johnson, S., Hepburn, C. G., Vidmar, M., et al. (2009). Perceived justice of compensation process for return-to-work: Development and validation of a scale. Psychological Injury and Law, 2, 225-237.

Frank, E., Kupfer, D. J., Buysse, D. J., Swartz, H. A., Pilkonis, P. A., Houck, P. R., et al. (2007). Randomized trial of weekly, twicemonthly, and monthly interpersonal psychotherapy as maintenance treatment for women with recurrent depression. The American Journal of Psychiatry, 164, 761-767.

Frasure-Smith, N., \& Lespérance, F. (2005). Depression and coronary heart disease: Complex synergism of mind, body, and environment. Current Directions in Psychological Science, 14, 39-43.

Frueh, B. C., Elhai, J. D., Acierno, R. (2010). The future of posttraumatic stress disorder in the DSM. Psychological Injury and Law, 3, 260-270. 
Frye v. United States, 293F. 1013, 34 ALR 145 (D. C. Cir 1923).

Gass, C. S., Williams, C. L., Cumella, E., Butcher, J. N., \& Kally, Z. (2010). Ambiguous measures of unknown constructs: The MMPI-2 Fake Bad Scale (aka symptom validity scale, FBS, FBS-r). Psychological Injury and Law, 3, 81-85.

Gatchel, R. J., Bo Peng, Y., Fuchs, P. N., Peters, M. L., \& Turk, D. C. (2007). The biopsychosocial approach to chronic pain: Scientific advances and future directions. Psychological Bulletin, 133, 581624.

Gelenberg, A. J., Freeman, M. P., Markowitz, J. C., Rosenbaum, J. F., Thase, M. E., Trivedi, M. H., Van Rhoads, R. S. (2010). Practice guideline for the treatment of patients with major depressive disorder. Washington, DC: American Psychiatric Association. Retrieved from http://www.psychiatryonline.com/pracGuide/ pracGuideTopic 7.aspx.

General Electric Company et al. vs. Joiner et ux., 522 U. S. 136 (1997)

Gervais, R. O., Ben-Porath, Y. S., Wygant, D. B., \& Green, P. (2007). Development and validation of a response bias scale (RBS) for the MMPI-2. Assessment, 14, 196-208.

Gervais, R. O., Ben-Porath, Y. S., Wygant, D. B., \& Green, P. (2008). Differential sensitivity of the response bias scale (RBS) and MMPI-2 validity scales to memory complaints. The Clinical Neuropsychologist, 22, 1061-1079.

Gervais, R. O., Ben-Porath, Y. S., \& Wygant, D. B. (2009a). Empirical correlates and interpretation of the MMPI-2-RF cognitive complaints (COG) scale. The Clinical Neuropsychologist, 23, 996-1015.

Gervais, R. O., Ben-Porath, Y. S., Wygant, D. B., \& Green, P. (2009b). Erratum: Differential sensitivity of the response bias scale (RBS) and MMPI-2 validity scales to memory complaints. The Clinical Neuropsychologist, 23, 549.

Ginzburg, K., Ein-Dor, T., \& Solomon, Z. (2009). Comorbidity of longitudinal study of war veterans. Journal of Affective Disorders, 123, 249-257.

Gironda, R. J., Clark, M. E., Ruff, R. L., Chait, S., Craine, M., Walker, R., et al. (2009). Traumatic brain injury, polytrauma, and pain: Challenges and treatment strategies for the polytrauma rehabilitation. Rehabilitation Psychology, 54, 247-258.

Gold, L. H., Anfang, S. A., Drukteinis, A. M., Metzner, J. L., Price, M., Wall, B. W., et al. (2008). AAPL practice guideline for the forensic evaluation of psychiatric disability. The Journal of the American Academy of Psychiatry and the Law, 36(Supplement 4), S3-S50.

Goldfreid, M. R. (2010). Evidence-based practice does not mean empirically supported therapy. Integrating Science and Practice, $1,14-17$.

Goldstein, S., \& Naglieri, J. A. (2009). Defining the evolving concept of impairment. In S. Goldstein \& J. A. Naglieri (Eds.), Assessing impairment: From theory to practice (pp. 1-4). New York: Springer Science + Business Media.

Gordeev, S. A. (2008). Cognitive functions and the state of nonspecific brain systems in panic disorders. Neuroscience and Behavioral Physiology, 38, 707-714.

Green, P. (2005). Green's world memory test user's manual. Edmonton: Green's.

Greiffenstein, M. F., Fox, D., \& Lees-Haley, P. R. (2007). The MMPI-2 fake bad scale in detection of noncredible brain injury claims. In K. B. Boone (Ed.), Assessment of feigned cognitive impairment: $A$ neuropsychological perspective (pp. 210-235). New York: Guilford.

Gupta, S., \& Bonanno, G. A. (2010). Trait self-enhancement as a buffer against potentially traumatic events: A prospective study. Psychological Trauma, 2, 83-92.

Haack, S. (2008). What's wrong with litigation-driven science? An easy in legal epistemology. Seton Hall Law Review, 38, 10531083.
Henry, G. I., Heilbronner, R., Mittenberg, W., \& Enders, C. (2006). The Henry-Heilbronner Index: A 15-item empirically derived MMPI-2 subscale for identifying probable malingering in personal injury litigants and disability claimants. The Clinical Neuropsychologist, 20, 786-797.

Heilbronner, R. L., Sweet, J. J., Morgan, J. E., Larrabee, G. J., Millis, S. R., \& Participants, C. (2009). American Academy of Clinical Neuropsychology consensus conference statement on the neuropsychological assessment of effort, response bias, and malingering. The Clinical Neuropsychologist, 23, 10931129 .

Heilbrun, K. (2001). Principles of forensic mental health assessment. New York: Kluwer.

Heilbrun, K., Grisso, T., \& Goldstein, A. M. (2009). Foundations of forensic mental health assessment. New York: Oxford University Press.

Hoffman, B. M., Papas, R. K., Chatkoff, D. K., \& Kerns, R. D. (2007). Meta-analysis of psychological interventions for chronic low back pain. Health Psychology, 26, 1-9.

Hofmann, S. G., Sawyer, A. T., \& Fang, A. (2010). The empirical status of the "new wave" of cognitive behavioral therapy. Psychiatry Clinics of North America, 33, 701-710.

Hopwood, C. J., Orlando, M. J., \& Clark, T. S. (2010). The detection of malingered pain-related disability with the Personality Assessment Inventory. Rehabilitation Psychology, 55, 307-310.

Howard, K. J., Kishino, N. D., Johnston, V. J., Worzer, W. E., \& Gatchel, R. J. (2010). Malingering and pain: Is this a major problem in the medicolegal setting? Psychology Injury and Law, 3, 203-211.

Hunter, L. R., \& Schmidt, N. B. (2010). Anxiety psychopathology in African American adults: Literature review and development of an empirically informed sociocultural model. Psychological Bulletin, 136, 211-235.

Ji, G., Sun, H., Fu, Y., Li, Z., Pais-Vieira, M., Galhardo, V., et al. (2010). Cognitive impairment in pain through amygdale-driven prefrontal cortical deactivation. The Journal of Neuroscience, 30, 5451-5464.

Johnstone, B., Schopp, L. H., Shigaki, C. L., \& Franklin, K. L. (2010). Forensic psychological evaluation in rehabilitation. In R. G. Frank, M. Rosenthal, \& B. Caplan (Eds.), Handbook of rehabilitation psychology (2nd ed., pp. 179-194). Washington: American Psychological Association.

Kane, A. W. (2010). Essentials of malingering assessment. In M. J. Ackerman (Ed.), Essentials of forensic psychological assessment (2nd ed., pp. 85-111). New York: Wiley.

Kane, A. W., \& Dvoskin, J. A. (2011). Evaluation for personal injury claims. New York: Oxford University Press.

Keefe, F. J., Rumble, M. E., Scipio, C. D., Giordano, L. A., \& Perri, L. M. (2004). Psychological aspects of persistent pain: Current state of the science. The Journal of Pain, 5, 195-211.

Kendall-Tackett, K. (2010). Depression, hostility, posttraumatic stress disorder, and inflammation: The corrosive health effects of negative mental states. In K. Kendall-Tackett (Ed.), The psychoneuroimmunology of chronic disease: Exploring the links between inflammation, stress, and illness (pp. 113-132). Washington: American Psychological Association.

King, D. W., Leskin, G. A., King, L. A., \& Weathers, F. W. (1998). Confirmatory factor analysis of the clinician-administered PTSD scale: Evidence for the dimensionality of posttraumatic stress disorder. Psychological Assessment, 10, 90-96.

Koch, W. J., Douglas, K. S., Nicholls, T. L., \& O’Neill, M. L. (2006). Psychological injuries: Forensic assessment, treatment, and law. New York: Oxford University Press.

Kubany, E. S., Ralston, T. C., \& Hill, E. E. (2010). Intense fear, helplessness, "and" horror? An empirical investigation of DSMIV PTSD criterion A2. Psychological Trauma: Theory, Research, Practice, and Policy, 2, 77-82. 
Kuhmo Tire Company v. Carmichael, 119S. Ct, 1167 (1999).

Kusnetz, S., \& Hutchison, M. (1979). A guide to the work-relatedness of disease (DHEW publication no. 79-116). Atlanta: NIOSH.

Larrabee, G. J. (2008). Aggregation across multiple indicators improves the detection of malingering: Relationship to likelihood ratios. The Clinical Neuropsychologist, 22, 666-679.

Laugharne, J., Lillee, A., \& Janca, A. (2010). Role of psychological trauma in the cause and treatment of anxiety and depressive disorders. Current Opinion in Psychiatry, 23, 25-29.

Lazar, S. G. (2010). The cost-effectiveness of psychotherapy in the treatment of depression. Integrating Science and Practice, 1, 26-31.

Leclair, N., Leclair, S., \& Brigham, C. R. (2009). The medical model of impairment. In S. Goldstein \& J. A. Naglieri (Eds.), Assessing impairment: From theory to practice (pp. 59-75). New York: Springer Science + Business Media.

Lees-Haley, P. R., English, L. T., \& Glenn, W. J. (1991). A fake bad scale on the MMPI-2 for personal injury claimants. Psychological Reports, 68, 203-210.

Liedl, A., \& Knaevelsrud, C. (2008). Chronic pain and PTSD: The perpetual avoidance model and its treatment implications. Torture, 18, 69-76.

Liedl, A., O’Donnell, M., Creamer, M., Silove, D., McFarlane, A., Knaevelsrud, C., et al. (2010). Support for the mutual maintenance of pain and post-traumatic stress disorder symptoms. Psychological Medicine, 40, 1215-1223.

Livesley, W. J. (2010). Confusion and incoherence in the classification of personality disorder: Commentary on the preliminary proposals for DSM-5. Psychological Injury and Law, 3, 304-313.

Long, M. E., \& Elhai, J. D. (2009). Posttraumatic stress disorder's traumatic stressor criterion: History, controversy, and clinical and legal implications. Psychological Injury and Law, 2, 167-178.

Main, C. J., Sullivan, M. J., \& Watson, P. J. (2008). Pain management: Practical applications of the biopsychosocial perspective in clinical and occupational settings (2nd ed.). New York: Elsevier

Margoshes, B. G., \& Webster, B. S. (2000). Why do occupational injuries have different health outcomes? In T. G. Mayer, R. J. Gatchel, \& P. B. Polatin (Eds.), Occupational musculoskeletal disorders (pp. 47-61). Philadelphia: Lippincott Williams \& Wilkinson.

Martelli, M. F., Nicholson, K., \& Zasler, N. D. (2007). Psychological approaches to comprehensive pain assessment and management following TBI. In N. D. Zasler, D. I. Katz, \& R. Z. Zafonte (Eds.), Brain injury medicine: Principles and practice (pp. 723 742). New York: Demos

Martelli, M. F., Nicholson, K., \& Zasler, N. D. (2008). Skill reacquisition after acquired brain injury: A holistic habit retraining model of neurorehabilitation. NeuroRehabilitation, 23, 115-126.

Mason, S., Turpin, G., Woods, D., Wardrope, J., \& Rowlands, A. (2006). Risk for psychological distress following injury. British Journal of Psychology, 45, 217-230.

Mayou, R. A., Ehlers, A., \& Bryant, B. (2002). Posttraumatic stress disorder after motor vehicle accidents: 3-year follow-up of a prospect of longitudinal study. Behaviour Research and Therapy, 40, 665-675.

McClintock, S. M., Husain, M. M., Rush, A. J., Knapp, R. G., Mueller, M., Petrides, G., et al. (2010). Evaluation of the effects on severe depression on global cognitive function and memory. CNS Spectrums, 15, 304-313.

McCracken, L. M., \& Eccleston, C. (2006). A comparison of the relative utility of coping and acceptance-based measures in a sample of chronic pain suffers. European Journal of Pain, 10, 23-29.

McCrea, M. A. (2008). Mild traumatic brain injury and postconcussion syndrome: The new evidence base for diagnosis and treatment. New York: Oxford University Press.
McFarlane, A. C. (2010). The delayed and cumulative consequences of traumatic stress: Challenges and issues in compensation settings. Psychological Injury and Law, 3, 100-110.

McGrath, R. E., Mitchell, M., Kim, B. H., \& Hough, L. (2010). Evidence for response bias as a source of error variance in applied assessment. Psychological Bulletin, 136, 450-470.

McNally, R. J. (2003). Progress and controversy in the study of posttraumatic stress disorder. Annual Review of Psychology, 54, 229-252.

Melton, G., Petrila, J., Poythress, N., \& Slobogin, C. (2007). Psychological evaluations for the courts: A handbook for mental health professionals and lawyers (3rd ed.). New York: Guilford.

Melzack, R. (2005). Evolution of the neuromatrix theory of pain. Pain Practice, 5, 85-94.

Melzack, R., \& Katz, J. (2006). Pain in the 21st century: The neuromatrix and beyond. In G. Young, A. W. Kane, \& K. Nicholson (Eds.), Psychological knowledge in court: PTSD, pain, and TBI (pp. 129-148). New York: Springer Science + Business Media.

Millon, T. (1997). Millon clinical multiaxial inventory-III manual (2nd ed.). Minneapolis: National Computer Systems.

Millon, T., Davis, R., Millon, C., \& Grossman, S. (2006). Millon clinical multiaxial inventory-III manual (3rd ed.). Minneapolis: National Computer Systems.

Morey, L. (1991). Personality assessment inventory: Professional manual. Odessa: Psychological Assessment Resources.

Morey, L. (2007). Personality assessment inventory: Professional manual (2nd ed.). Lutz: Psychological Assessment Resources.

Naifeh, J. A., Richardson, J. D., Del Ben, K. S., \& Elhai, J. D. (2010). Heterogeneity in the latent structure of PTSD symptoms among Canadian veterans. Psychological Assessment, 22, 666-674.

Nelson, N. W., Hoelzle, J. B., Sweet, J. J., Arbisi, P. A., \& Demakis, G. J. (2010). Updated meta-analysis of the MMPI-2 symptom validity scale (FBS): Verified utility in forensic practice. The Clinical Neuropsychologist, 24, 701-724.

Nicholson, K., \& Martelli, M. F. (2007). Malingering in psychological injury: TBI, chronic pain, and PTSD. In G. Young, A. W. Kane, \& K. Nicholson (Eds.), Causality of psychological injury: Presenting evidence in court (pp. 373-514). New York: Springer Science + Business Media.

Norman, S. B., Stein, M. B., Dimsdale, J. E., \& Hoyt, D. B. (2008). Pain in the aftermath of trauma is a risk factor for post-traumatic stress disorder. Psychological Medicine, 38, 533-542.

O’Donnell, M. L., Creamer, M., Pattison, P., \& Atkin, C. (2004). Psychiatric morbidity following injury. The American Journal of Psychiatry, 161, 507-514.

Olatunji, B. O., Cisler, J. M., \& Deacon, B. J. (2010). Efficacy of cognitive behavioral therapy for anxiety disorders: A review of meta-analytic findings. Psychiatry Clinics of North America, 33, $557-577$.

Otis, J. D., Gregor, K., Hardway, C., Morrison, J., Scioli, E., \& Sanderson, K. (2010). An examination of the co-morbidity between chronic pain and posttraumatic stress disorder in U.S. veterans. Psychological Services, 7, 126-135.

Overall, J. E., \& Gorham, D. R. (1962). Brief psychiatric rating scale. Psychological Reports, 10, 799-812.

Parikh, S. V., Segal, Z. V., Grigoriadis, S., Ravindran, A. V., Kennedy, S. H., Lam, R. W., et al. (2009). Canadian Network for Mood and Anxiety Treatments (CANMAT) clinical guidelines for the management of major depressive disorder in adults. II. Psychotherapy alone or in combination with antidepressant medication. Journal of Affective Disorders, 117, S15-S255.

Patten, S. B., Kennedy, S. H., Lam, R. W., O’Donovan, C., Filteau, M. J., Parikh, S. V., et al. (2009). Canadian Network for Mood and Anxiety Treatments (CANMAT) clinical guidelines for the management of major depressive disorder in adults. I. Classifi- 
cation, burden and principles of management. Journal of Affective Disorders, 117, S5-S14.

Palyo, S. A., \& Beck, J. G. (2005). Post-traumatic stress disorder symptoms, pain, and perceived life control: Associations with psychosocial and physical functioning. Pain, 117, 121-127.

Peterson, D. B., \& Paul, H. (2009). Using the International Classification of Functioning, Disability and Health (ICF) to conceptualize disability and functioning in psychological injury and law. Psychological Injury and Law, 2, 205-214.

Pledger, C. (2003). Discourse on disability and rehabilitation issues: Opportunities for psychology. The American Psychologist, 58, 279-284.

Pole, N., Gone, J. P., \& Kulkarni, M. (2008). Posttraumatic stress disorder among ethnoracial minorities in the United States. Clinical Psychology: Science and Practice, 15, 35-61.

Poleshuck, E. L., Gamble, S. A., Hoffman-King, D., Cerrito, B., Rosairo-McCabe, L. A., \& Giles, D. E. (2010). Interpersonal psychotherapy for co-occurring depression and chronic pain. Professional Psychology: Research and Practice, 41, 312-318.

Pope, K., \& Vasquez, M. (2011). Ethics in psychotherapy and counseling: A practical guide. New York: Wiley.

Powers, M. B., Halpern, J. M., Ferenschak, M. P., Gillihan, S. J., \& Foa, E. B. (2010). A meta-analytic review of prolonged exposure for posttraumatic stress disorder. Clinical Psychology Review, 30, 635-641.

Poyner, G. (2010). Psychological evaluations of veterans claiming PTSD disability with the department of veterans affairs: A clinician's viewpoint. Psychological Injury and Law, 3, 130-132.

Reed Group (2009). Medical disability advisor, 6th ed. Retrieved 10 June 2009 from http://www.meicaldisabilityadvisor.com/.

Reitan, R. M., \& Wolfson, D. (1985). The Halsted-Reitan neuropsychological test battery: Theory and clinical interpretation. Tucson: Tucson Neuropsychology.

Ribbe, D. (1996). Psychometric review of traumatic screening instrument. In B. H. Stamm (Ed.), Measurement of stress, trauma, and adaptation (pp. 386-387). Lutherville: Sidran.

Richards, P. M., \& Kirk, J. W. (2010). Traumatic brain injury across the lifespan: A neuropsychological tutorial for attorneys. Psychological Injury and Law, 3, 3-24.

Robinson, J. S., \& Larson, C. (2010). Are traumatic events necessary to elicit symptoms of posttraumatic stress? Psychological Trauma: Theory, Research, Practice, and Policy, 2, 71-76.

Robinson, M. E., \& O'Brien, E. M. (2010). Chronic pain. In R. G. Frank, M. Rosenthal, \& B. Caplan (Eds.), Handbook of rehabilitation psychology (2nd ed., pp. 119-132). Washington: American Psychological Association.

Rogers, R. (2008). An introduction to response styles. In R. Rogers (Ed.), Clinical assessment of malingering and deception (3rd ed., pp. 3-13). New York: Guilford.

Rogers, R., Bagby, R. M., \& Dickens, S. E. (1992). Structured interview of reported symptoms. Odessa: Psychological Assessment Resources.

Rogers, R., Sewell, K. W., \& Gillard, N. D. (2010). Structured Interview of Reported Symptoms (SIRS) and professional manual. Lutz: Psychological Assessment Resources.

Rondinelli, R. D., Genovese, E., Katz, R. T., Mayer, T. G., Müller, K. L., Ranavaya, M. I., et al. (2008). Guides to the evaluation of permanent impairment (6th ed.). Chicago: American Medical Association.

Rubenzer, S. (2009). Posttraumatic stress disorder: Assessing response style and malingering. Psychological Injury and Law, 2, 114-142.

Rubenzer, S. (2010). Review of the Structured Inventory of Reported Symptoms-2 (SIRS-2). Open Access Journal of Forensic Psychology, 2, 273-286.

Ruff, R. M., \& Jamora, C. W. (2009). Myths and mild traumatic brain injury. Psychological Injury and Law, 2, 34-42.
Sarason, I. G., Johnson, J. H., \& Siegel, J. M. (1978). Assessing the impact of life changes: Development of the life experiences survey. Journal of Consulting and Clinical Psychology, 46, 932946.

Sareen, J., Cox, B. J., Stein, M. B., Afifi, T. O., Fleet, C., \& Asmundson, G. J. G. (2007). Physical and mental comorbidity, disability, and suicidal behavior associated with posttraumatic stress disorder in a large community sample. Psychosomatic Medicine, 69, 242-248.

Sbordone, R. J. (2010). Neuropsychological tests are poor at assessing the frontal lobes, executive functions, and neurobehavioral symptoms of traumatically brain-injured patients. Psychological Injury and Law, 3, 25-35.

Sbordone, R. J., \& Ruff, R. M. (2010). Re-examination of the controversial coexistence of traumatic brain injury and posttraumatic stress disorder: Misdiagnosis and self-report measures. Psychological Injury and Law, 3, 63-76.

Schatman, M. E., \& Gatchel, R. J. (2010). Introduction to special issue on traumatically induced pain: Assessing and addressing controversies. Psychology Injury and Law, 3, 165-168.

Schatman, M. E., \& Sullivan, J. (2010). Whither suffering? The potential impact of tort reform on the emotional and existential healing of traumatically injured chronic pain patients. Psychology Injury and Law, 3, 182-202.

Schultz, I. Z. (2009). Determining disability: New advances in conceptualization and research. Psychological Injury and Law, 2, 199-204.

Schultz, I. Z. (2010). Neurocognitive disorders in DSM-V: Forensic perspective. Psychological Injury and Law, 3, 271-288.

Schultz, I. Z., \& Gatchel, R. J. (2005). Handbook of complex occupational disability claims: Early risk identification, intervention, and prevention. New York: Springer Science + Business Media.

Sellbom, M., \& Bagby, R. M. (2008). Response styles on multiscale inventories. In R. Rogers (Ed.), Clinical assessment of malingering and deception (3rd ed., pp. 182-206). New York: Guilford.

Sharp, T. J., \& Harvey, A. G. (2001). Chronic pain and posttraumatic stress disorder: Mutual maintenance? Clinical Psychology Review, 21, 857-877.

Simms, L. J., Watson, D., \& Doebbeling, B. N. (2002). Confirmatory factor analyses of posttraumatic stress symptoms in deployed and non-deployed veterans of the Gulf War. Journal of Abnormal Psychology, 111, 637-647.

Simon, R., \& Gold, L. (2004). Textbook of forensic psychiatry. Washington: American Psychiatric.

Sinclair, D. C., II. (2010). Epidemiology in the courtroom: An evidence-based paradigm for the determination of causation in compensation environments. Special Section: World Congress On Neck Pain, 52, 456-461.

Slick, D. J., Sherman, E. M. S., \& Iverson, G. L. (1999). Diagnostic criteria for malingered neurocognitive dysfunction: Proposed standards for clinical practice and research. The Clinical Neuropsychologist, 13, 545-561.

Smith, A., \& OPA Auto Task Force. (2010). Ontario Psychological Association Guidelines for assessment and treatment in auto insurance claims. Ontario Psychological Association: Toronto, Ontario. Retrieved from http://www.psych.on.ca/files/members/ OPA Auto Practice Guidelines July292010 July 30 2010.pdf.

Smith, T. W., Uchino, B. N., Berg, C. A., Florsheim, P., Pearce, G., Hawkins, M., et al. (2007). Hostile personality traits and coronary artery calcification in middle-aged and older married couples: Different effects for self-reports versus spouse ratings. Psychosomatic Medicine, 69, 441-448.

Sullivan, M. J. L., Davidson, N., Garfinkel, B., Siriapaipant, N., \& Scott, W. (2009). Perceived injustice is associated with heightened pain behavior and disability in individuals with whiplash injuries. Psychological Injury and Law, 2, 238-247. 
Tate, D. G., \& Pledger, C. (2003). An integrative conceptual framework of disability: New directions for research. The American Psychologist, 58, 289-295.

Teasell, R. W., McClure, J. A., \& Walton, D. (2010). Toward an evidence-based approach to whiplash injuries. Pain Research \& Management, 15, 285-286.

Thomas, M. L., \& Locke, D. E. C. (2010). Psychometric properties of the MMPI-2-RF somatic complaints (RC1) scale. Psychological Assessment, 22, 492-503.

Tolin, D. F., \& Foa, E. B. (2006). Sex differences in trauma and posttraumatic stress disorder: A quantitative review of 25 years of research. Psychological Bulletin, 132, 959-992.

Tollison, C. D., \& Langley, J. C. (1995). P3: Pain patient profile manual. Minneapolis: National Computer Systems.

Tombaugh, T. N. (1996). Test of memory malingering. Tonawonda: Multi-Health Systems.

United States Government Printing Office (2009). Federal Rules of Evidence. Washington: United States Government Printing Office. http://judiciary.house.gov/hearings/printers/111th/ evid2009.pdf.

Vittengl, J. R., Clark, L. A., Dunn, T. W., \& Jarrett, R. B. (2007). Reducing relapse and reocurrence in unipolar depression: A comparative meta-analysis of cognitive-behavioral therapy's effects. Journal of Consulting Clincial Psychology, 5, 475-488.

Vlaeyen, J. W., \& Linton, S. J. (2000). Fear-avoidance and its consequences in chronic musculoskeletal pain: A state of the art. Pain, 85, 317-332.

Wachtel, P. L. (2010). Beyond "ESTs" problematic assumptions in the pursuit of evidence-based practice. Psychoanalytic Psychology, 27, 251-272.

Wald, J., \& Taylor, S. (2009). Work impairment and disability in posttraumatic stress disorder: A review and recommendations for psychological injury research and practice. Psychological Injury and Law, 2, 254-262.

Weathers, F., \& Ford, J. (1996). Psychometric review of PTSD checklist (PCL-C, PCL-S, PCL-M, and PCL-PR). In B. H. Stamm (Ed.), Measurement of stress, trauma, and adaptation (pp. 250-251). Lutherville: Sidran.

Wechsler, D. (1997). WAIS-III administration and scoring manual. San Antonio: Psychological Corporation.

Williams, C. L., Butcher, J. N., Gass, C. S., Cumella, E., \& Kally, Z. (2009). Inaccuracies about the MMPI-2 Fake Bad Scale in the reply by Ben-Porath, Greve, Bianchini, and Kaufmann (2009). Psychological Injury and Law, 2, 182-197.

World Health Organization. (2001). International classification of functioning, disability and health: ICF. Geneva: World Health Organization.

Work Loss Data Institute. (2008). Official disability guidelines. Encinitas: Work Loss Data Institute.
Worzer, W. E., Kishino, N. D., \& Gatchel, R. J. (2009). Primary, secondary, and tertiary losses in chronic pain patients. Psychological Injury and Law, 2, 215-224.

Wygant, D. B., Sellbom, M., Gervais, R. O., Ben-Porath, Y. S., Stafford, K. P., Freeman D. B., \& Heilbronner, R. L. (2010). Further validation of the MMPI-2 and MMPI-2 RF response bias scale: Findings from disability and criminal forensic settings. Psychological Assessment, 22, 745-756.

Young, G. (2007). Causality: Concepts, issues, and recommendations. In G. Young, A. W. Kane, \& K. Nicholson (Eds.), Causality of psychological injury: Presenting evidence in court (pp. 49-86). New York: Springer Science + Business Media.

Young, G. (2008a). Psychotherapy for psychological injury: A biopsychosocial and forensic perspective. Psychological Injury and Law, 1, 287-310.

Young, G. (2008b). Causality and causation in law, medicine, psychiatry, and psychology: Progression or regression? Psychological Injury and Law, 1, 161-181.

Young, G. (2008c). Psychological injury and law: An integrative model. Psychological Injury and Law, 1, 150-160.

Young, G. (2008d). Somatization, and medically unexplained symptoms in psychological injury: Diagnoses and dynamics. Psychological Injury and Law, 1, 224-242.

Young, G. (2010a). Chronic pain in the DSM IV and the DSM 5 draft: The pain of it all. Psychological Injury and Law, 3, 320-322.

Young, G. (2010b). Causes in the construction of causal law: A psycho-ecological model. International Journal of Law and Psychiatry, 32, 73-83.

Young, G., \& Johnson, R. (2010). Posttraumatic stress disorder in the DSM-5: Group difference commentary. Psychological Injury and Law, 3, 314-319.

Young, G., \& Kane, A. W. (2007). Causality in psychology and law. In G. Young, A. W. Kane, \& K. Nicholson (Eds.), Causality of psychological injury: Presenting evidence in court (pp. 13-48). New York: Springer Science + Business Media.

Young, G., \& Shore, R. (2007). Dictionary of terms related to causality, causation, law, and psychology. In G. Young, A. W. Kane, \& K. Nicholson (Eds.), Causality of psychological injury: Presenting evidence in court (pp. 87-135). New York: Springer Science + Business Media.

Young, G., Kane, A. W., \& Nicholson, K. (2006). Psychological knowledge in court: PTSD, pain, and TBI. New York: Springer Science + Business Media.

Young, G., Kane, A. W., \& Nicholson, K. (2007). Causality of psychological injury: Presenting evidence in court. New York: Springer Science + Business Media.

Zinbarg, R. E., Mashal, N. M., Black, D. A., \& Flückiger, C. (2010). The future and promise of cognitive behavioral therapy: A commentary. Psychiatry Clinics of North America, 33, 711-727. 